\title{
Transfer of Print-Based Academic Reading Strategies to On-Screen Reading
}

\author{
Hanadi Khadawardi \\ Dept. English Language Institute, King Abdulaziz Univeristy \\ Jeddah, Saudi Arabia
}

Received: December 1, 2020 Accepted: December 16, 2020 Published: December 18, 2020

doi:10.5296/ijele.v9i1.18091ＵRL: https://doi.org/10.5296/ijele.v9i1.18091

\begin{abstract}
This article contributes to the existing body of research on academic reading practices in the 21 st century, by focusing on on-screen reading in the technological age. The study offers an insight into the nature of on-screen reading and reflects the authentic on-screen academic reading experiences of international postgraduate readers in the UK educational context. This was achieved by investigating participants' reading comprehension strategies while reading on-screen academic research articles, compared with those employed when engaged in print-based reading. This study also scrutinizes L2 readers' use of digital affordances and their use of e-resources while comprehending on-screen texts. Case study and interpretive qualitative approaches have been adopted in the present research study. Thematic and content analysis and a constant comparative method (CCM) have been applied to analyze the data. Although new on-screen reading strategies emerged from the data, the results reveal a transfer of print-based reading techniques to on-screen reading. This demonstrates a move from a traditional literacy to a digital one in which readers manipulate the strategies that they are already aware of, and are capable of, in order to read a text on-screen. Surprisingly, readers were much more effective: and employed more strategies and interacted more deeply with the printed text than with the on-screen text. The results from this study have led to the proposal of suggested models for interpreting on-screen L2 academic reading interactions. A number of pedagogical practices are suggested and recommended for preparing L2 readers for further academic study which could be equally applicable and useful for L1 academic reading instructions in the 21 st century, including the reshaping of reading skills textbooks to accommodate and meet the needs of reading comprehension practices in the technological age and promoting learners' digital academic literacy. These practices may be useful to teachers when teaching on-screen reading strategies for specific academic purposes in digital universities.
\end{abstract}

Keywords: L1, L2, affordances, digital academic literacy, technology, reading skills, cognition 


\section{Introduction}

\subsection{Reading Comprehension in the Digital era}

The commencement of the digital age has brought about considerable change to educational sectors around the world, in particular the higher education sector in the UK, which has witnessed a proliferation of technology applications (Goodfellow \& Lea, 2013). Universities and colleges have digitized their management information systems and now use virtual learning environments, digital tools and materials to assist teaching and learning (Sharpe, Beetham, Freitas, \& Conole, 2010). Moreover, the increasing prevalence of digital libraries, including digital scholarly journals and publisher platform libraries, have resulted in dramatic changes to learning and knowledge related interactions in universities (Goodfellow \& Lea, 2013). Digitization in colleges, universities and libraries has therefore changed the widely known concept of academic literacy, or 'the ability to communicate competently in an academic discourse community' (Wingate 2015, p.6) to digital academic literacy. In this regard, a complete transition from writing on traditional paper to typing on-screen has occurred, while the transition from reading a printed paper to on-screen texts remains incomplete (Mark, 2015).

At the other end of the spectrum, English language as a medium of instruction and learning is a growing global phenomenon in the 21st century (Dearden 2014 \& Robson 2013), the mastery of which is imperative to ensure information can be obtained, exchanged and communicated (Cenoz \& Jessner 2000; Wood 2001). Considering this fact, many international students have opted to study in the West, particularly the UK, which is the second most popular destination after the United States for international students to continue their studies. Each year, over 600,000 international students from 200 different countries come to study at schools, colleges and universities in the UK and a further 600,000 enroll in short English language courses (Robson, 2013). A total of 216,466 study visas were approved in 2015 for non-EU nationals to study for undergraduate and postgraduate degrees, according to data from the Home Office (UK, 2015). The number of non-UK students rises to 435,495 when EU students are included (UKCISA, 2015).

These phenomena have had an enormous impact on second and foreign language students in academic contexts and on reading practices. The recent proliferation of academic electronic texts, e-resources and the increasing use of on-screen presentations has brought about dramatic changes in the ways in which university students interact and comprehend digital information (Liu, 2008). Park et al. (2012) noted that university students increasingly read on screen as the use of digital libraries and electronic documents becomes normalized and learners spend a considerable amount of time reading documents electronically. Thus, the contemporary reading format differs considerably from that in preceding centuries. University students in the 21 st century find themselves exposed to vast numbers of electronic texts and documents, on-screen facilities and resources provided by many UK universities (Goodfellow \& Lea, 2013), which require specific reading comprehension strategies. The above facts highlight the need to investigate and reconsider the reading practices of non-native readers of English in the digital age. 
Several researchers have argued that the current reading digital environment requires new dimensions and approaches. For example, Darnton (2009), the director of Harvard University Library, stated that readers today 'feel the ground shifting beneath their feet, tipping toward a new era that will be determined by innovations in technology' (p. xiii). Reading practices have changed due to advances made in computer technology and the digital environment. Globally, there has been an exponential growth in the amount of information available online in digital format: it is predicted that by 2020 , about $70 \%$ of the world's information will be influenced by electronic practices (Eshet-alkalai \& Geri, 2009) As Liu (2005) noted, 'Digital media contributes to a transformative shift in reading' (p.701). In the current digital age, academic reading skills and technology are largely connected to academic contexts. The existence of digital libraries provides a useful example of recent academic reading behavior. These libraries have been established to make data accessible and include vast amounts of digital information and electronic documents. The majority publish as well as purchase electronic texts (Brown 2001). Many university libraries in the US and the UK offer access to a campus network, using Blackboard or WebCat to store electronic documents (Ibid.). Lynch (2001, cited in Brown 2001) also stated that publishers, such as the National Academies Press have been offering their publications free of charge on the Internet for several years.

Clearly, students' ability to read, interact, comprehend, evaluate and use electronic information effectively is a key concern and a necessity for success in the current digital age. Unfortunately, mastery of this skill is not easy, and many students encounter serious difficulties when attempting to effectively read and comprehend digital academic texts. Birkerts (1994, cited in Liu 2005) argued that readers lack the ability to interact and deeply engage with digital text. Liu and Huang (2008) commented, 'yet the practices of online reading in networked environments are not well understood' (p.623). These findings highlight the need for further research into on-screen academic reading comprehension in the academic setting, in this, the digital age.

It is now possible to argue that the rapid growth in information technology, access to diverse and disparate knowledge, the increased popularity of computer applications, the Internet, digital libraries and electronic academic texts in Western universities have led to an increased need to explore how readers read digital texts effectively. As the digital world, has merged with academia, digital reading has consequently become increasingly common and important for both students and academics. Contemporary educational settings require students to locate digital information and to read, analyze, interpret, evaluate and use materials digitally. If students are not able to carry out these digital processes, they may encounter difficulties when attempting to function as literate students in a digital educational environment. It is thus essential to ensure that university students have the academic digital competences and capabilities to interact effectively with electronic academic texts and to enable readers to keep pace with digital changes.

\section{Review of the Literature}

\subsection{Reading from Old to new: On-screen Reading}


Contemporary academic digital information has influenced L1 and L2 university students' reading practices in terms of reading academic texts in a specific field of study in an electronic or digital mode. E-texts are viewed via a screen using two different formats. Hypertext involves several links and provides nonlinear information via several forms, such as webpages, graphics, sound, video and animation (Ketabi, Ghavamnia, \& Rezazadeh, 2012; Nielsen, 1990). It links textual materials, ideas and sources (Chen 2010; Salmerón et al. 2010; Park \& Kim 2011). The other format of on-screen text is static, prepared and stored in advance, such as PDF and JPG files. It also involves reading with multiple modalities and additional sources, such as graphics, animations, video, audio and hyperlinks (Hartman 2011).

Reading on-screen in this study is defined as the act of interacting with an e-text presented through electronic screens using digital strategies and e-resources to achieve specific purposes. It requires competences (schemata), particularly digital schema and capabilities, to enhance digital reading comprehension and to solve digital reading challenges.

\subsection{Strategies for On-screen Academic Reading}

The focus of this research is on the cognitive reading comprehension strategies that enable readers to comprehend a text. Cognitive reading strategies are defined as learning techniques, behaviors and problem-solving that make reading more effective and efficient (Oxford \& Crookall 1989; Anderson 1999). According to Wallace (2001) reading strategies are the readers' conscious actions employed to comprehend a written text. They are the ways that readers use to manage their interaction with written text (Ibid.). Graesser (2012) asserted that cognitive reading strategies are employed by readers in order to improve some aspects of reading comprehension and/or handle reading obstacles. Reading strategies indicate how readers conceive of a task, how they make sense of what they read and what they do when they do not understand (Koda 2005). In short, such strategies are processes used by the reader to enhance reading comprehension and overcome comprehension challenges and failures.

Current research into second and foreign language reading has begun to focus on the reading strategies used by L2 readers to process L2 written text. Researchers suggest that L2 readers use a variety of reading strategies to assist them with the comprehension, acquisition, storage and retrieval of information from a written text, Hudson (2007). These strategies comprise scanning for specific details, using background knowledge, recognizing main ideas, re-reading, selective reading, adjusting speed, self-generating questions, summarizing, predicting and guessing unknown words from the context.

Reading researchers have categorized reading strategies into three groups: linguistic, paralinguistic and semantic. These strategies can be employed by L2 readers to comprehend reading text effectively (Wright $\&$ Brown 2006). First, linguistic strategies involve a process of associating the written elements with its corresponding sounds by means of reading aloud (Wright \& Brown 2006). Linguistic strategies also involve analyzing new items by using similar known items, identifying grammatical categories and understanding sentence structure (Ibid.). Second, paralinguistic strategies 'aim at making texts accessible from the outset' and allow L2 readers to gain confidence and increase motivation (Wright \& Brown 
2006, p.23). Readers utilize paralinguistic strategies to improve their reading comprehension by recognizing text genre, predicting the type of language used by the author, and using punctuation as cues to interpret meanings (Wright \& Brown 2006). Third, L2 readers can comprehend reading text via semantic strategies that involve two types of reading: skimming and scanning (Ibid.).

Other researchers have classified reading strategies according to a three-phase approach: before, during, and after reading strategies. The before reading stage includes strategies such as engaging readers' background (Frager 1993; Varaprasad 1996), previewing and anticipating the content of the text, comments on visuals and acknowledging new words (Saricoban 2002). The during-reading stage consists of strategies, such as understanding the writer's purpose and intention, understanding the text structure and the logical organization of the text, using inferencing and judging, skimming (surveying the general information), scanning (looking for specific information) and finding answers to specific questions (Varaprasad 1996). The post-reading stage includes strategies, such as making connections, reviewing the first two stages, deep analysis and critiquing the text and summarizing the reading passage (Saricoban 2002).

The discussion now turns from paper-reading strategies to on-screen reading strategies. Recently, reading researchers have attempted to differentiate between the required reading strategies for paper and for digital reading. The literature raises questions about the differences between paper and digital reading strategies. In this regard, Park and Kim (2011) conducted a study to investigate the reading-strategies of three adult English language learners when they read digital texts in hypermedia learning environments. The researchers found that most of the participants employed common paper reading strategies to read digitally. They also found that the participants used two new reading strategies for digital reading, namely hypermedia and computer accessories such as using a mouse pointer as a substitute for pen and pencil, using menu and navigation options and using multimedia resources.

Several studies have investigated and identified specific digital reading strategies used by readers when they read digital text. For example, Anderson (2003) conducted a study to examine the role of second language reading strategies within the context of digital reading tasks for 247 EFL and ESL readers. He adapted the Survey of Reading Strategies (SORS) that comprises 38 items relating to three reading strategy categories: problem-solving reading strategies, support reading strategies and global reading strategies. He named it the Online Survey of Reading Strategies (OSORS). Another research study was conducted in the same field by Yutdhana (2007) on 205 Thai graduate students from three faculties: Social Sciences, Health Sciences and Sciences and Technology. The study used the OSORS survey to explore the digital reading strategies used by second language graduate students and to examine whether students from the three faculties employed different digital reading strategies. The findings revealed that graduate students most frequently used the global reading strategies and the problem-solving strategies, while the support reading strategies were used the least.

The previous studies demonstrate that digital reading requires readers to employ the 
traditional paper reading strategies as well as different types of reading strategies such as using hyperlinks, navigational strategies, and computer accessories. However, these studies did not compare the paper and digital reading strategies employed by the same readers to precisely assess the differences between reading strategies for text in paper and digital form. Reorganize: Very few studies have been conducted, in this regard, for example, Zaki et al. (2009) investigated the digital and printed reading strategies used by 109 ESL undergraduates at a university in Malaysia. The findings of the two surveys: SORS and OSORS revealed that three reading strategies - global, support and problem-solving, were employed when reading digital and printed formats. However, it found that digital readers employ significantly more strategies compared to print-based readers. That is, more global and problem-solving strategies are employed when reading digitally compared to printed-paper. In contrast to the above results, support strategies for printed reading have significantly higher mean values compared to digital reading. However, relying only on the survey to compare paper and digital reading strategies. It is not sufficient to assess the differences between the two. Therefore, there is a need to scrutinize the differences between the actual reading strategies used for paper-based and digital reading by the same readers via other means, such as think-aloud protocols and stimulated recalls. By doing this, a complete picture of the components of digital reading strategies will be seen.

In a similar vein, there are a few studies (Akyel \& Erçetin 2009; Ketabi et al. 2012; Park \& Kim 2011) which have investigated readers' hypermedia reading strategies and explored new strategies for digital reading. Akyel and Erçetin (2009) investigated the reading strategies of ten undergraduate English learners enrolled in an ELT Department at a Turkish university while reading a hypermedia document. The researchers found that readers employed new types of reading strategies, such as navigational strategies and use of annotations when reading the hypermedia document. Ketabi et al. (2012) investigated the reading strategies of twenty-three Persian EFL graduate students while reading a hypermedia text format. It found that readers employed several sorts of strategies, such as referring to annotations, referring to the glossary, paraphrasing in L1/L2, re-reading, using background knowledge, skipping/skimming, formulating questions, and making predictions. However, there is a dearth of research investigating digital reading strategies when it comes to digital static texts. Following a presentation and discussion of previous research studies concerning on-screen reading strategies, the present research adopts three main reading strategy categories, outlined by the OSORS survey (Anderson 2003), to investigate readers' on-screen reading strategies.

1. Problem-solving reading strategies (PROB)

2. Support reading strategies (SUP)

3. Global reading strategies (GLOB)

The following section presents another factor, reading for different academic purposes, that also structures and manipulates readers' reading strategies.

\subsection{Different Academic Purposes and On-screen Reading}

In the case of print-based reading, studies have differentiated between two main purposes of 
reading: reading for entertainment and reading for study purposes. Researchers have distinguished between the strategies that are employed by readers in the two cases. Generally, people read newspapers, magazines, recipes, TV guides, etc. for entertainment. Students, in contrast, read other genres, such as text books, research articles, and reports with the intention of being able to perform academic tasks such as taking a test, learning, gaining and integrating specific information, writing a paper or an assignment, discussing in class, evaluating, critiquing, or giving a presentation (Grabe, 2012; Grabe \& Stoller, 2011; Plakans, 2009) Studies on reading show that different reading purposes require readers to process texts differently (Linderholm et al. 2008; Plakans 2009; Koda 2005; Broek et al. 2001). For example, a study conducted by Linderholm et al. (2008) examined the reading times and the monitoring capacity of college student readers. In their study, readers read an expository text under one of two reading purpose conditions - reading for study and reading for entertainment - and then answered comprehension questions about the text. The results of the study indicated that the working memory capacity of readers' reading times were slower when reading for entertainment purposes than when reading for study purposes. Researchers concluded that the reading purpose affects cognitive and metacognitive reading processing and recall patterns (Linderholm et al. 2008).

When it comes to on-screen reading, which is the main concern of this study, researchers have also investigated how readers read for different purposes on the Internet. They have made a distinction between different Internet reading purposes, such as reading to locate specific information: reading to acquire general knowledge about a topic, and reading for entertainment (S. Zhang \& Duke, 2008). These different purposes of reading on the Internet may lead to the use of different reading strategies. In this regard, Slatin (1994) categorises two types of Internet readers: the user and the browser. The user is the one who 'enters the hyper document in search of specific information and leaves it again after locating that information'. The browser is the one who 'wanders rather aimlessly (but not carelessly) through an area, picking things up and putting them down as curiosity or momentary interest dictates' (p. 159). Zhang and Duke (2008) explored the variance that occurs in L1 adult good readers' reading strategies when they read on-screen text for three different reading purposes, namely, to search for specific information, to acquire general knowledge, and for entertainment. The researchers found that the readers adopted different reading strategies for the different Internet reading purposes. That is, readers went through three distinct phases when reading to locate specific information and two phases when they read in order to acquire general knowledge. Readers used strategies to evaluate information and make decisions only when they read to locate specific information. Regarding reading for enjoyment, researchers found that readers skipped the initial search phase used by readers for the other two reading purposes, because they already had a favorite website in mind before starting to read. Another strategic difference between reading for these three purposes is the reader's strategy to choose, enter and re-enter the search query words (Ibid.). The researchers also reported that readers intentionally avoid advertisements when reading for locating specific information and acquiring general knowledge, while they follow advertisement links when reading for entertainment. Moreover, readers read graphics differently for each reading purpose. When they want to locate specific information, they pay little attention to graphics, 
and when they read to acquire general knowledge or for the purpose of entertainment, they pay more attention to photos, cartoons, charts and graphs (Zhang and Duke 2008).

However, a review of the literature indicates that few studies have been carried out on the purposes of postgraduates' academic reading such as comprehension in order to learn or write; their on-screen reading purposes and the reading strategies that they employ particularly within the UK educational context. More research is required to distinguish the aims of academic reading in relation to the different reading formats (on-screen and printed text) and the associated reading strategies used by second language postgraduate students. It is also clear that there is a difference between finding and selecting the appropriate text and reading the text itself. The researcher's focus in the current study is not on how readers find the text, but on how they read and comprehend the text once they find it, although the internet allows the reader to browse and navigate during reading.

\subsection{Reading for Comprehension}

When it comes to academic reading purposes, reading for comprehension is the most basic purpose for reading and the common underlying process that is activated during reading. According to Chen et al. (2011), all reading purposes should be preceded by the comprehension of the written content. For example, readers who are reading to search for specific information, to learn, to integrate information, to produce a written or oral outcome or to evaluate should comprehend the written material in advance to be able to proceed to the next purpose.

Graesser (2012) summarized the general components of the comprehension process included in several definitions as: 1) the interpretation of the text; 2) the use of prior knowledge; and 3) the construction of a coherent representation of the content of the text. It is acknowledged that reading comprehension requires many supporting skills. It demands the 'ability to mentally interconnect different events in the text and form a coherent representation of what the text is about' (Kendeou et al. 2007, p.28). It also includes processing of vocabulary knowledge, background knowledge and knowledge of grammar, metacognitive awareness and cognitive reading strategies (Koda 2005; Qian 2002; Gelderen et al. 2004). Grabe and Stoller (2011) stated that reading for comprehension is a complex process affected by numerous factors, such as language abilities, goals and motivations.

Gunderson (2008) distinguished between three types of reading comprehension: literal comprehension, inferential comprehension and critical or evaluative comprehension. Literal comprehension, which means understanding based on syntactic and semantic knowledge, is the process of understanding texts on the surface level of the written content. Inferential comprehension requires the reader to understand the content of the text in depth rather than at surface level. Readers should understand the writer's idea and purpose, form generalizations about the text, and predict outcomes. Evaluative comprehension refers to the reader's judgment of the text in regard to validity, factual information versus opinion and the ability to transfer the acquired knowledge to other situations. Comprehension in this study refers to the reader's ability to derive meaning from the text by understanding the surface level of ideas and continuing to understand the deeper meanings including comprehending information and 
language. It also involves connecting the ideas that are presented and conveyed in a text using different sorts of schemata such as digital, formal, and content (competences) and employing reading approaches including reading comprehension strategies and digital affordances (capabilities).

The discussion above highlights the fact that more research studies are needed to understand the reading comprehension strategies that are employed for different academic study purposes by second language postgraduate students. The following section highlights the role that genre and discipline play in reading comprehension strategies.

\subsection{Genre, Discipline and On-screen Reading}

This section discusses the use of the term 'genre' in this work, in relation to its effect on reading strategies. Genre is a 'rhetorical strategy used within a professional culture to organize knowledge in the form of professional action to achieve the objectives of professional communities' (Bhatia 2004, p.179). It represents a standardized form of language that is particular to specific institutions and communities, such as a formal letter, oral presentations, interviews and reports (Grabe 2012; Roldán-Riejos \& Úbeda-Mansilla 2006; Hudson 2007). With reference to the written genre, Grabe (2012) stated that genre is 'specific patterns and systems of text organization that reflect the goals of the writer, the purpose of writing specific texts, and the expectations of skilled readers' (p.248). The written genre is 'a social practice through which writers interact with readers' (Soliday 2011, p.2). The written genre can include many different types of texts that are available to readers and each type has its own distinctive characteristics, such as a letter, sign, newspaper, or message. Hudson (2007) classified written text into two main types, description fiction, such as novels and plays, and nonfiction, such as essays, reports, articles, textbooks, and conference papers.

In this vein, researchers attempted to differentiate between genre and sub or part genre. For example, the New York Times articles, and Weekly World news articles are a sub-genre of the newspaper article genre, and survey articles, and review articles are considered to be sub-genres of the research article genre, (Hudson 2007). Also, within the academic research articles genre, researchers categorized other sub-genres such as abstract, introduction, methodology, results, and discussion. Each part has its own defined purpose and organization (Samraj 2005).

The digital text genre domain comprises a considerable number of genres that already exist in the printed world. These genres, such as e-books, e-newspaper, e-magazines and e-reports, have been modified to suit the digital medium. However, there are new digital genres that have no obvious paper equivalent, such as the homepage (Askehave \& Ellerup Nielsen, 2005; Dillon \& Gushrowski, 2000), blogs (Miller \& Shepherd, 2009) and Wikipedia (Tereszkiewicz, 2010).

Digital genres have been grouped into five different kinds: reproduced, adapted, emergent, spontaneous and emerging genres (Tereszkiewicz, 2010). Reproduced web genres are replicated genres, which have been completely transferred from the traditional media to the web, such as dictionaries, official forms, scholarly papers and scientific journals. Adapted 
genres are similar to the reproduced ones in terms of their transferability but they exhibit a degree of difference in their pragmatic and structural features when compared to their counterparts in the traditional media, such as e-books and e-zines. Emergent genres include a considerable number of the generic aspects of their traditional counterparts but are characterized by significant developed functional attributes that make them dependent on e-media. In addition, their conventions and rules of usage have been acknowledged by their authors and users such as blogs, chats and e-mails. Spontaneous genres have no counterpart in traditional media and are entirely dependent upon new media. They are formed by the rules that govern the functions of the web such as homepages, error pages, portals and search engines. Emerging genres are genres that are still in the process of development and lack conventions, which need to be acknowledged by a community of users.

Although there is a growing body of research on print-based reading comprehension and related written genres, few studies have investigated the reading processes and strategies used in relation to digital genres. Researchers such as the RAND group (Snow, 2002) demonstrated that distinct text features and text genre influence the reading comprehension process and require readers to react differently to the written text. In this regard, researchers investigated the reading strategies that readers employ when they read narrative and expository texts (Grabe 2012; Yoshida 2012; Primor et al. 2011). For instance, Park (2010) scrutinized the differences between the reading strategies of one hundred and fifteen Korean college students when they read authentic expository/technical texts versus authentic narrative texts. The researcher used the Survey of Reading Strategy (SORS) to measure the students' reading strategy use (Park 2010). The survey revealed that the Korean EFL college students used reading strategies with high frequency when they read authentic expository/technical texts in English and with lower frequency when reading authentic narrative texts. More specifically, Korean students used Global and Support strategies more when they read authentic expository/technical texts than when they read authentic narrative texts (Ibid.). This study confirms that there are differences in the reading process depending on the type of text.

In addition, research on reading has focused on the effect of different written texts in different disciplines on readers' reading strategies. Researchers are concerned with differences in disciplines within the genre and the relationship between the variations within disciplines and the ways in which genres are formulated. For example, Hewings (2006) stated that 'variations in the characteristic patterns of academic writing occur not only from genre to genre but within genres from discipline to discipline' (p.14). According to Hyland (2009), disciplines affect the use of language to enable engagement with others sharing a common background. They structure the written work and provide specific conventions and particular expectations that make texts meaningful for specific groups. In this vein, Parodi (2008) defined disciplinary text as a discourse genre with the 'macropurpose [...] to present, to a specialized audience, one or more topics on a particular subject matter belonging to a field of study' (p.492).

Hyland (2009) summarized the effect of different disciplines namely, the Sciences, Social Sciences and Humanities on the written genre. Science writing, such as Biology, Engineering 
and Physics highlight a gap in knowledge, present a hypothesis related to this gap, and report experimental findings to support this in a standard format consisting of Introduction, Methods, Results and Discussion. The Humanities disciplines, such as Literature, History and Philosophy usually rely on a specific approach, such as case studies and narratives. They present and prove their claims via arguments. The Social Sciences, such as Sociology and Economics adopt the methods of the Sciences, but apply them to human data to give an explicit interpretation. Hyland (2009) also distinguished between the different ways that the three different disciplines ask research questions, address literature, criticize ideas and present arguments by comparing the use of citations, reporting verbs, hedges, self-mention, directives and bundles.

The differences that exist between disciplines led reading researchers to investigate the reading strategies that readers use to read and comprehend texts in different disciplines. For example, Jafari and Shokrpour (2012) investigated the reading strategies of eighty one male and female Iranian ESP students studying at the Shiraz University of Medical Sciences from different disciplines (Environmental Health, and Occupational Health and Safety, and Midwifery) when they read authentic expository texts in English. They used the Survey of Reading Strategies (SORS) of Sheorey and Mokhtari (2001). The survey revealed that the two different disciplines used different reading strategies. That is, students majoring in Environmental Health used more reading strategies, such as using reference materials, going back and forth in the text and translating than those majoring in Occupational Health and Safety and Midwifery. Park also (2010) used the Survey of SORS to investigate the reading strategies of Korean students from the different disciplines such as Education, Social Sciences, Engineering, Humanities, and Business. He found significant differences in the overall use of reading strategies across the four academic major groups. The Education, Social sciences and Humanities majors used all three strategy categories more frequently than the Engineering students. Students majoring in Education, Social Sciences and Humanities reported using the reading strategies more frequently than the Business students who in turn reported using them more frequently than the Engineering students. These studies argue that reading in different disciplines requires different strategies. However, none of the previous research studies have used relevant techniques to scrutinize the actual and applicable reading strategies that are employed by readers in different disciplines. Instead, the majority of the studies rely on the readers' self-reports.

In the academic genre, discipline domain researchers have examined the rhetorical features of the sub-genre of research articles including the Abstract, Introduction, Methodology, Results, Discussion, and Conclusion in different disciplines. However, there are no studies that investigate the process of reading that occurs during each part of the research article in a range of disciplines. For example, Ruiying and Allison (2004) conducted a study to describe and understand the macro-structural organization of research articles in the discipline of Applied Linguistics. Martin (2003) investigated the rhetorical variation in experimental Social Sciences, in his research article entitled 'Abstracts' written in English and Spanish. Ozturk (2007) explored the degree of variability in the structure of research article 'Introductions' in the two sub-disciplines of Applied Linguistics. Lim (2010) compared the 


\section{$\triangle$ Macrothink}

'Results' sections of research articles in Applied Linguistics and Education. Samraj (2005) compared the generic structure of the research article focusing on 'Introductions' and 'Abstracts' in two related fields, Conservation Biology and Wildlife Behaviour. He found that the research article 'Introductions' and 'Abstracts' in Conservation Biology were similar in function and organization to the two genres in Wildlife Behaviour. He also found that the 'Abstracts' from both were similar in rhetorical structure as they contained the purpose, results and conclusions. Basturkmen (2012) examined the 'Discussion' sections of articles in Dentistry with reference to the 'Discussion' sections in Applied Linguistics. He found that the structure of the 'Discussion' sections in Dentistry included similar moves and rhetorical purposes to Applied Linguistics, namely reviewing the study, summarizing results, reporting a specific result or related results and commenting on them. Although, numerous studies have examined the differences and similarities between the research article genre and its sub-genres within a range of disciplines, very few studies have investigated and compared the reading strategies used when reading on-screen research articles and their sub-genres in different disciplines. In addition, few research studies have scrutinized the effects of interacting with the different sub-genres of a research article on readers' use of reading strategies during on-screen reading.

\subsection{Affordances and Limitations of On-screen Reading}

Digital affordances and the limitations of digital reading have been controversial subjects within the field of digital reading research. There are researchers who advocate the benefits of digital reading to readers, while others argue that digital reading is ineffective due to its limitations. Recently, a group of educators have realized the potential of computer technology and have demonstrated increased interest in using it as a tool to augment digital academic reading comprehension (Park et al. 2012; Labbo 2006; Day \& Lloyd 2007). One digital affordance for reading is multimedia. Reinking (2001) noted that multimedia programs are not limited to textual information and can take the form of video, sound and pictures, all of which have an effective role in making digital texts comprehensible. This sort of digital affordance provides second language readers with tools that have the potential to facilitate their L2 general, academic and technical vocabulary and also their reading comprehension (Abraham 2007). Moreover, digital readers have the opportunity to use several kinds of dictionaries or thesauri to look for word comparisons, related words, synonyms, antonyms, sample sentences, basic grammar, irregular verbs and word-by-word translations (Montelongo \& Herter 2010).

Researchers also demonstrated that digital readers can easily read illustrated texts and navigate related topics as well as check information. Electronic text (via its navigational services) can aid reading comprehension challenges that are due to limited background knowledge (Anderson-Inman 2009). For instance, readers can consult an online encyclopaedia to gain more information related to the subject under discussion (Montelongo \& Herter 2010). Coiro and Dobler (2007) stated that the Internet has support tools for digital reading comprehension, such as the use of search engines to navigate multi-layered websites and monitor the appropriateness of their pathway through a complex network of connected text. Digital readers can use hypermedia technology presented in text embedded links, images, 
audio, video and discussion space in order to access a wider range of information. Liu (2005) stated that digital texts give the reader the choice of reading distinct parts of a text (in no particular order) and to navigate to other related sites for further information. In an earlier study of L2 reading with digital glosses, Lomicka (1998) conducted research on twelve college students enrolled in a French course in order to investigate the effects of multimedia reading software on reading comprehension. Lomicka (1998) found that glosses in a hypermedia played an effective role in helping students to understand the passage.

Annotations are directly integrated with printed reading material. However, electronic text has its own forms. There are a small number of existing studies that attempt to characterize or analyze markings made on e-documents. The studies include those undertaken by Marshall and Brush (2002) and Qayyum (2008). These studies established various kinds of annotations during electronic reading. These include: base markings; highlighting; underlining; compound markings; notes consisting of one to two sentences; cryptic expressions consisting of one to two words; symbols such as '?', '!' and numbers; circles; squares; asterisks; and stars. They also include other symbols, such as arrows, drawings, lines, and single or double lines in the margins. Moreover, Qayyum (2008) noted that the readers used electronic markings during digital reading to emphasize a passage, to separate the article into various topics or ideas and to remember certain aspects of the article that could be used in a later discussion. Digital readers also use symbols to link ideas and to create text zones for singling out similar ideas.

There have been further investigations on the positive effects of technological reading dynamics on readers' reading performance. For example, Piolat et al. (1997) noted that digital readers can increase the speed of their reading via several technical procedures. That is, they can move quickly through portions of text using the scroll bar. This also provides an approximation of the location of the reading matter, such as whether the reader is at the beginning, middle or the end of the text (Piolat, Roussey, \& Thunin, 1997). Readers can also quickly and easily move the text using the page-up and page-down keys (Ibid.). Further research studies have established that the ability to use large font sizes is another advantage of digital reading (Burk 2001). Moreover, different web pages can be opened simultaneously on screen and placed either side-by-side or super-imposed upon each other. Readers can then easily switch between several windows. Szymanska and Kaczmarek (2011) stated that digital materials can be adjusted, zoomed and manipulated for comfortable and clear reading.

Chuene, Lepota and Hans (2014) mentioned three main tangible benefits that the e-text affords to readers. First, e-text has a text to speech feature which enables readers who have a visual impairment to listen to the text (Lynne Anderson-Inman \& Horney, 2007). Second, the portability feature of e-text, which enables readers to carry all their documents, including books and papers, in one slim machine, provides an incentive for on-screen reading (Annand, 2008). Third, on-screen reading has a positive environmental effect, as it saves paper and thus trees and also cuts down on CO2 (Carbon Dioxide) emissions.

Most of the previously mentioned affordances of digital reading can be summarized in line with Anderson-Inman's (2004) (Anderson-Inman \& Horney 2007; Anderson-Inman 2009) 
eleven categories of e-text resources, namely:

1. Presentational Resources

2. Navigational Resources

3. Translational Resources

4. Explanatory Resources

5. Illustrative Resources

6. Summarizing Resources

7. Enrichment Resources

8. Notational Resources

9. Collaborative Resources

10. Evaluative Resources

\section{Instructional Resources}

Anderson-Inman's e-resources model is adopted as the starting point for the current study to investigate readers' use of e-resources while reading on-screen academic texts.

In the previously mentioned literature, e-texts are presented as support tools that enhance academic reading and comprehension. However, some researchers claim that digital reading has several drawbacks. Olive and Rouet (2008) claimed that digital reading is suboptimal and less effective than paper reading. Liu (2005) found that during digital reading, less time is spent on in-depth reading, and sustained attention. Levy (1997) maintained that digital reading is fragmented and less concentrated. Horton et al. (1995) found that digital reading relies on flipping, scanning, browsing, selecting, and locating information in a text to get a sense of the whole document. Horton et al. (1995) believed that the feature of intensive reading is absent during digital reading. Lynch (2001, cited in Chou 2012) claimed that students use digital reading materials only for browsing, checking and deciding what to read, while they print longer texts for careful and deep reading. Moreover, Shabani et al. (2012) maintained that printed documents are more suitable for in-depth reading and note taking than digital ones. They justified their claims with students' responses which demonstrated that taking notes from printed documents does not distract from the reading process, while in electronic reading, readers need to interact with the mouse and the keyboard to annotate. Dyson and Haselgrove (2000) and Brown (2001) reported that rapid skimming and scanning were most frequently used in digital reading, while detailed reading was used less frequently. It is clear that the majority of the studies mentioned above, focus on the drawbacks of on-screen reading and seem oblivious to its affordances. They do not delve into its effectiveness of on-screen reading when compared with paper-based reading due to characteristics such as nonlinearity, the ease of multitasking, and the manner in which it supports scanning. 


\section{Ml Macrothink}

This study argues that digital reading offers a number of important intuitive affordances that help enhance readers' reading performance. Moreover, the positive characteristics of e-text outweigh the negative, especially for L2 postgraduate student readers. The affordances of digital reading such as interactivity, immediacy of accessing information, and the convergence of text, images, audio and video are lacking in the printed text. Researchers may claim that digital reading is superficial and not efficient. However, this view may be because students who prefer printed reading sometimes have limited knowledge of technology's benefits and are therefore unable to take advantage of them. good part of their academic career reading from printed-paper and hard copies, so when it comes to digital reading, they may find it confusing and therefore reject it. The negative factors mentioned above (see Olive \& Rouet 2008; Levy 1997; Dyson \& Haselgrove 2000; Brown 2001; Horton et al. 1995; Liu 2005) might be eliminated if readers knew how to use and manipulate digital materials effectively. Furthermore, these drawbacks of digital reading, such as reliance on browsing and scanning, are not sufficiently significant to outweigh the benefits of digital reading for L2 academic readers. Moreover, scanning and skimming are also considered essential reading strategies, which readers need to master and practice when reading texts whether in printed or digital format.

The present study puts forward the hypothesis that on-screen reading is an effective practice capable of scaffolding and enhancing 21 st century readers' reading comprehension and learning, particularly if the readers are capable of effectively employing its affordances and overcoming its challenges.

\section{Research Design}

The study population for this research consisted of postgraduate female students studying at the University of Southampton in the UK. This included five female Master's students studying different subjects: two from Health Science, one from Psychology, one from Education and one from Accounting. The other group of participants consisted of fifteen female PhD students majoring in different subjects: Accounting and Finance, Management, Design, Engineering, Psychology, Computer Science and Health Science. The research subjects were selected based on a non-random method (purposive sampling) in order to obtain the richest and most detailed information to answer the research questions. They were selected on the basis of homogeneity sharing the following characteristics:

\section{They are Arab}

2. They are female

3. They are native speakers of Arabic

4. They study in the UK

5. They learnt English as a foreign language in their home country

6. They took a language course (at least three months) before commencing their postgraduate degree 
7. They are postgraduate students

8. Their English language proficiency is upper-intermediate (i.e. 6.5) as estimated from their IELTS exam scores

The Case study approach was chosen for the current study for several reasons. First, because it makes it possible to closely observe and collect in-depth and detailed data pertaining to a particular group (postgraduate students), to explore the ways in which they read digitally in a specific context (the UK) and their perceptions of L2 digital academic reading. According to Lier (2011), the case study spotlights a specific group in a specific context. Thus, it relates the reading practices of the subjects to their current educational context, with the aim to offer an understanding of its influence on behavior and processes. The case study approach therefore involves interrogating data within its actual context (Cohen et al. 2011) thus making it possible to scrutinize the actual reading practices of readers in the UK educational sector. Cohen et al. (2011) asserted that the case study consists of data emerging from detailed and specific investigations collected over time (Hartley 2004). Thus, it is a key method for the current study that investigates, observes and documents changes in students' L2 academic digital reading. In addition, it provides the opportunity to explore participants' perceptions of their reading practices, the changes that have occurred, the factors that have affected their reading practices, and their perceptions of those factors. Johnson (1991) stated that a 'Case study can provide rich information about an individual learner. It can inform us about the processes and strategies that individual L2 [second language] learners use to communicate and learn, how their personalities, attitude, and goals interact with the learning environment, and about the precise nature of their linguistic growth' (p.76). Several sorts of data methods were employed to collect the required data and achieve triangulation and trustworthiness. First, the think Aloud protocol was used in the current study to increase understanding of how postgraduate students read digital L2 research articles in their field of study by scrutinizing observable cognitive behavior related to reading for comprehending and learning. The participants were asked to vocalize their thoughts while attempting to comprehend a reading passage. Thus, they had to read their-self chosen research articles on the researcher's personal laptop as it has the software program (Camtasia), which assists in the purpose of the study. After receiving a signal, the participants had to start the Think-Aloud (TA) during print and digital reading as well as while using digital technology during digital reading, and to justify their choices to accomplish their intended goals. Second, Stimulated Recalls (SR) method is employed in the current study as it enriches the data, mitigates the drawbacks of the TA protocol and extends the scope of the research study. First, it provides the researcher with indirect access to the readers' cognitive processes through the interpretation of those processes by the reader during their silent reading in the videotaped think-aloud session, as some readers do not verbalize every aspect of their reading comprehension. The SR method has made it possible for the researcher to make the most of the data collection method by asking questions and getting explanations and clarifications about the silent pauses in the reading process. Third, semi-structured interviews were used to allow new insights into the experiences and perspectives of the participants and permit the gathering of in-depth data. It is a flexible method that enables respondents to speak freely about themselves (Dörnyei 
2007), so in the current study, it allowed unexpected data to emerge. Most importantly, the semi-structured interview has been chosen for use in the current study, instead of structured questions or a questionnaire as there are several variables to be considered which would cause difficulties. It also enables the researcher to investigate the participants' L2 reading experiences and perceptions in depth.

The study took place at the University of Southampton, in the UK. PhD and Master's students from different disciplines were recruited via the voluntary response and snow-ball sampling methods. A brief introduction about the study was given to them and they were asked to prepare and bring two research articles from their field of study that they had not previously read, one printed and the other online. The researcher prepared the material and directed the video camera at the reader's seat.

The participants met individually with the researcher in the specified room and filled in the demographic questionnaire prior to starting the Think-Aloud protocol. It only needed five minutes to complete as it is relatively short and concise. The researcher chose to start with the demographic questionnaire as some of the responses would help to interpret the subjects' reading behaviors during the think-aloud protocol, for example, knowing that the participant's medium of instruction during her Bachelor's degree was Arabic, enhanced the researcher's interpretation of the reader's reading behavior enabling the researcher to focus on the questions during the SR and the interview on the role of Arabic for understanding English material.

The think-aloud followed by the stimulated recalls were conducted with each participant twice; once with the participant reading from the printed paper format and once with them reading on-screen. The value of having the same participant read one printed article and another one on-screen is that it reveals the differences and similarities between reading in different formats. Initially, a demonstration about the think-aloud and stimulated recall was provided in the first language of the participants (Arabic in this context). The TA sessions, researcher's field's notes, SRs followed by the interviews were conducted twice with the Master's students.

Regarding the Master's participants, the reason for collecting the data a month after the starting date of the students' program was that at the beginning of their course, the students are not fully concentrating on their academic reading. This is due to practical issues that need to be resolved, such as visas and accommodation. During all three methods, the researcher informed the participants that they were free to report and respond in Arabic or English, according to their preference, in order to encourage richer responses and more in-depth information. The meeting began with a warm-up conversation. The researcher then provided the participant with the consent form to be read and signed. The researcher explained the consent form and made sure that the participants understood everything related to their participation in the study.

In the current study, the use of self-selected texts was adopted in the think-aloud protocols in order to gather data about the authentic reading experience of postgraduate students, their actual L2 digital academic reading strategies, the challenges that they face, ways to overcome 


\section{Macrothink}

these challenges and the use of digital affordances while reading research articles in their field of study. To avoid any consequences of repeat reading (which is not the focus of the current study), the participants chose unfamiliar research articles that they had not read before. Each participant chose a printed article, and an electronic one covering the same topic based on instructions that were provided along with the invitation letter to harmonize the general aspects of the chosen reading articles between the participants. However, there is no attempt to harmonize the type of texts in terms of content and language complexity between the readers as the researcher in the present study aimed to achieve an authentic reading experience. Although the text itself is not the focus and it is not part of the present research to investigate the effect of different text types on students' academic reading comprehension strategies, an initial investigation of the text types that the students selected to read during the study reveals that they are generally similar in their use of the academic style and register, grammar and language, but differ in content. Adobe Acrobat was used as the reading application for digital reading, as according to Qayyum (2008), it is widely used for publishing web documents.

\section{Finding and Discussion}

\subsection{On-screen Functional Reading Comprehension Strategy Categories and Sub-strategies}

As this study aims to explore readers' utilization of technology and the nature of the on-screen reading strategies they use during actual academic reading, via think-aloud protocols and SRs methods, the Online Survey of Reading Strategies (OSORS) is initially adapted in the current study as they represent the main functional strategies used by readers:

\section{Support (SUP)}

\section{Problem-solving (PROB)}

\section{Global (GLOB)}

(Anderson 2003)

However, the research does not make use of the OSORS reading sub-strategies, as these were originally formulated for use via the survey method, which does not feature in this study. Instead, some of the reading strategies suggested by Huang et al. 2009 are adopted, namely:

\section{Using grammar resources}

2. Adjusting the reading speed

3. Making visual presentations of ideas (mapping)

\section{Reading aloud}

\section{Having a purpose}

\section{Previewing}

7. Using electronic dictionaries and locating keywords 
(Huang et al. 2009)

Furthermore, other reading techniques have been adopted from Chun and Thompson's (2008) study in addition to the reading strategies of Huang et al. (2009):

\section{Scanning, marking the text}

2. Re-reading

3. Skipping

4. Translating using hardcopies

5. Using visual aids

6. Using context

7. Previewing

8. Paraphrasing

9. Using background knowledge and personal experience

\section{Anticipating}

\section{Formulating questions}

\section{Identifying main idea}

\section{Taking notes}

\section{Summarising}

\section{Planning}

\section{Attending selectively}

(Chun and Thompson 2008)

The justifications for the choice of the previous strategies are varied. Firstly, Chun and Thompson's (2008) strategies represent the two main reading processes (bottom-up and top-down) which are essential in second language reading comprehension and one of the areas on which the current study focuses. Secondly, Chun and Thompson (2008); and Huang et al. (2009) grouped the selected reading strategies that were previously mentioned according to the actual reading processes used by university students, as explained in previous studies. Thirdly, they were proposed by second language readers in the academic field. Fourthly, these strategies are adopted in the current study as they are considered to be reliable reading strategies employed by second language readers during actual reading and scrutinized via think-aloud protocols. 


\section{Macrothink}

The researcher in the present study grouped the aforementioned selected sub-strategies into the three reading categories, according to their function (see Table 1, for an illustration). For example, changing the reading rate and translation are categorized as 'problem-solving' reading strategies, as their functionality is to enable readers to solve comprehension problems. Strategies that support reading comprehension are classified as 'support' reading strategies, which include marking the text and summarizing. Finally, strategies including previewing and using background knowledge are classified as 'global' reading strategies, as these enable readers to manage their reading and invoke their own experience to help comprehend the text.

The sub-reading strategies are analyzed in this study according to two main themes:

1. Their function for example, problem-solving, supporting and global.

2. Their application during interaction with different levels of text, including text level, section level, paragraph level, sentence level and word level.

Table 1. Reading strategy categories - Definitions and examples

\begin{tabular}{|c|c|c|}
\hline Functional reading strategy & Definition & Example \\
\hline $\begin{array}{l}\text { 1. Problem-solving } \\
\text { reading strategies } \\
\text { (PROB) }\end{array}$ & $\begin{array}{l}\text { Mechanisms that enable readers } \\
\text { to solve comprehension } \\
\text { problems and overcome reading } \\
\text { comprehension challenges }\end{array}$ & $\begin{array}{l}\text { - Re-reading } \\
\text { - Using context } \\
\text { - Parsing } \\
\text { sentences }\end{array}$ \\
\hline $\begin{array}{l}\text { 2. Support reading } \\
\text { strategies (SUP) }\end{array}$ & $\begin{array}{l}\text { Mechanisms that aid and foster } \\
\text { readers' reading comprehension } \\
\text { and enable readers to achieve a } \\
\text { better understanding of the text }\end{array}$ & $\begin{array}{l}\text { - Marking the } \\
\text { text } \\
\text { - Taking notes } \\
\text { - Reviewing }\end{array}$ \\
\hline $\begin{array}{l}\text { 3. Global reading } \\
\text { strategies (GLOB) }\end{array}$ & $\begin{array}{l}\text { Mechanisms that enable readers } \\
\text { to manage and monitor their } \\
\text { reading process and involve } \\
\text { their previous experience to } \\
\text { comprehend the text }\end{array}$ & $\begin{array}{l}\text { - Having a } \\
\text { purpose in } \\
\text { mind } \\
\text { - Planning } \\
\text { - Anticipating }\end{array}$ \\
\hline
\end{tabular}


In the current study, while interacting with the academic text on-screen, the readers frequently employed strategies that were not part of the original reading strategy scheme in order to achieve comprehension. This study identified a new set of reading strategy categories and twenty-two sub-strategies. Table 2, presents only the new reading strategies and outlines their function. These strategies are categorized according to the previously selected reading strategy functions: GLOB, SUP and PROB. The data also led to the addition of a fourth functional reading strategy: critical reading (CRT). This fourth category has been given a critical function as a group of sub-reading strategies were directed toward critically thinking about the content of the text. In the present study, the new set of sub-strategies is grouped as follows: problem-solving reading strategies (PROB) which include, pausing, thinking and pointing: support reading strategies (SUP) which include, vocalizing electronically, confirming, pausing, thinking, pointing, continuing to read, mentally visualizing text content, making connections between text content, changing the physical reading position, using computer functions: global reading strategies (GLOB) which include, pausing, thinking, using text references and making connections between ideas: and critical reading strategies (CRT) which include, evaluating the information, evaluating the source of the information, evaluating the language and evaluating the style.

Table 2. Newly identified set of on-screen reading comprehension strategies

\begin{tabular}{|c|c|c|c|}
\hline \multicolumn{4}{|c|}{ New on-screen reading strategies } \\
\hline $\begin{array}{l}\text { 1. Problem-solving } \\
\text { reading } \\
\text { strategies } \\
\text { (PROB) }\end{array}$ & $\begin{array}{ll}\text { 2. Support } \\
\text { reading } \\
\text { strategies }\end{array}$ & $\begin{array}{l}\text { 3. Global } \\
\text { reading } \\
\text { strategies } \\
\text { (GLOB) }\end{array}$ & $\begin{array}{l}\text { 4. Critical } \\
\text { reading } \\
\text { strategies } \\
\text { (CRT) }\end{array}$ \\
\hline $\begin{array}{l}\text { 1. Pausing } \\
\text { 2. Thinking } \\
\text { 3. Pointing }\end{array}$ & 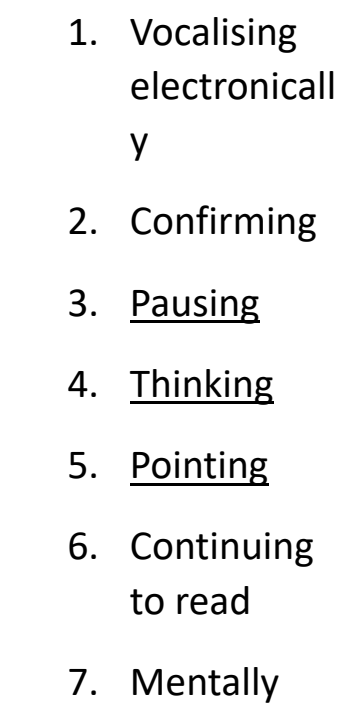 & $\begin{array}{l}\text { 1. Pausing } \\
\text { 2. Thinking } \\
\text { 3. Using text } \\
\text { references } \\
\text { 4. } \underline{\text { Connecting }} \\
\underline{\text { ideas }}\end{array}$ & $\begin{array}{l}\text { 1. Evaluating } \\
\text { the } \\
\text { informatio } \\
\mathrm{n} \\
\text { 2. Evaluating } \\
\text { the source } \\
\text { of the } \\
\text { informatio } \\
\mathrm{n} \\
\text { 3. Evaluating } \\
\text { the }\end{array}$ \\
\hline
\end{tabular}




\begin{tabular}{|r|r|r|}
\hline $\begin{array}{l}\text { visualising } \\
\text { text content }\end{array}$ & language \\
8. $\begin{array}{l}\text { Connecting } \\
\text { text content } \\
\text { 9. Using } \\
\text { computer } \\
\text { functions }\end{array}$ & & Evaluating \\
& & \\
\hline
\end{tabular}

Two of the original sub-strategies have been removed as neither of them were used during the current study by any of the readers under investigation. These are parsing sentences and using hard copy dictionaries. However, the categorization of some of the new sub-strategies is confusing, as four sub-strategies can be listed under more than one strategy type, as they have multiple functions (see underlined strategies in Table 2). In order to resolve this issue, TA and SR data were revisited and re-analyzed to identify the reasons underlying the use of these sub-strategies, in order to categorize them more accurately in relation to the main strategies.

Closer examination of the type and frequency of all the reading strategy categories and sub-reading strategies reveals that on-screen academic reading for comprehension requires various sorts of strategies. During on-screen reading, readers utilized diverse functional types of strategies to assist comprehension: either to solve a problem, support their reading comprehension, interact with the text globally or to critically evaluate the content. However, the frequency with which these strategies were utilized during the readers' on-screen L2 academic reading varies significantly. The analysis also reveals that although readers utilized various sorts of strategies during their on-screen reading, their overall utilization of each strategy was low, i.e. most strategies were used with low frequency.

Figure 1 presents the frequency with which different reading strategies were used to engage with on-screen texts. It demonstrates that a range of strategies were used to solve comprehension problems and to support reading comprehension. Readers also frequently employed background knowledge to globally assist comprehension. However, they rarely interacted deeply with the text on-screen and read critically 


\section{On-screen Functional Academic Reading Comprehension Strategies}

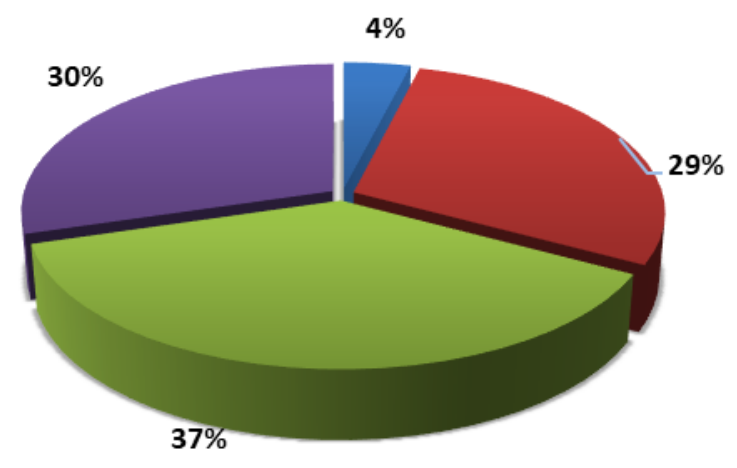

— Critical Reading Strategies (54) / m2.7

— Global Reading Strategies (394) / m19.7

- Problem-Solving Reading Strategies (512) / m25.6

- Support Reading Strategies (404)/ m20.2

Figure 1.The frequency (number of overall instances) of the on-screen academic functional reading strategies employed by participants $(n=20)$

As evidenced, the most frequently employed strategy was that of problem-solving (37\%). For example, all readers often translated, changed their reading speed, paused, pointed and re-read sections of text. Supportive reading strategies were also frequently employed (30\%). For example, all readers vocalized, annotated and confirmed as they went along. The third most frequently employed strategy was the global reading strategy (29\%). For example, all readers skipped, used background knowledge, previewed and identified main ideas. Critical reading strategies, by contrast, were used much less frequently (4\%).

\subsection{Print-based functional reading comprehension strategy categories and sub-strategies}

It was found that the readers used the four functional categories of reading strategies during their print-based academic reading comprehension, namely critical (CRT), global (GLOB), problem-solving (PROB) and support (SUP) reading strategies.

Figure 2 compares the frequency with which different reading strategy categories were employed during print-based reading. 


\section{Print-based Functional Academic Reading Comprehension Strategies}

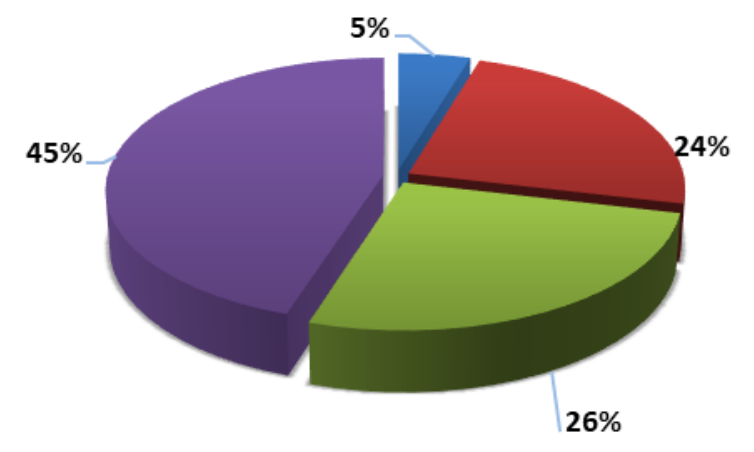

n Critical Reading Strategies (130) / m6.5

n Global Reading Strategies (665) / m33.25

- Problem Solving Reading Strategies (731) / m36.55

n Support Reading Strategies (1249) / m62.45

Figure 2. The frequency (number of overall instances) of the print-based academic functional reading strategies employed by participants $(n=20)$

The evidence shows that the most frequently employed strategy was that of support reading strategies $(45 \%)$. For example, readers often vocalized, annotated, confirmed and changed their reading speed. Problem-solving strategies were also frequently employed (26\%). For example, readers were translating, pausing and re-reading text as they went along. The third most employed strategy was the global reading strategy (24\%). For example, readers were skipping text, engaging their background knowledge, previewing and identifying main ideas. Critical reading strategies, by contrast, were used much less frequently $(5 \%)$.

In both formats, readers were utilizing a wide range of the same types of strategy: i.e. PROB, SUP, GLOB and CRT reading strategies. These results match those observed in earlier studies. For example, Bolanos (2012) found that readers in both kinds of environments employed similar strategies: meaning negotiating, meaning enhancing, meaning reinforcing, meaning generating, and information checking. Similarly, Park and Kim (2011) found that college level ESL learners employed print-based reading strategies while reading texts on-screen. Konishi (2003) found that global strategies, which were employed during digital reading were similar to those strategies used when reading from paper.

The frequency of use of these types of strategy differs between the two formats. A comparison of the frequency with which various reading strategies are employed during on-screen and paper reading reveals that all four types of strategies (support, problem-solving, global and critical) are used more frequently when reading on paper than when reading on-screen. However, the findings of the current study do not support the previous research. Zaki et al. (2009) found that during on-screen reading readers employ more problem-solving and global strategies than during print-based reading. A possible explanation for this might be 
that readers in the current study were more engaged with the paper text than the one on-screen, as they employed more reading strategies during their paper reading in order to enable them to comprehend the text. This might also indicate that the readers were more likely to comprehend the paper text than the one on-screen. An additional consideration is that Majid et al.(2010) found that proficient adult readers employ more reading strategies than less proficient readers. Similarly, Demiröz (2010) stated that successful readers employ more reading strategies than poor or less successful readers. Accordingly, from the current study, it is possible to hypothesize that readers read more proficiently from printed paper than they do from on-screen text, as they employed more strategies while reading printed paper. An in-depth analysis of, and comparison between, the sub-strategies and the main strategies that the readers employed during their on-screen reading also clearly reveals the differences between the types of sub-strategies used by readers during paper and on-screen reading.

Contrary to all expectations, comparisons between paper and on-screen reading sub-strategies reveal that readers use more sub-strategies when reading on paper. In other words, during on-screen reading, readers use fewer sub-strategies. Therefore, readers only engaged in those essential components of the reading process known to involve full comprehension, analysis and evaluation when reading on paper. This is because the readers used strategies, such as evaluating information, identifying main ideas and connecting ideas more frequently during their paper-based reading than during their on-screen reading. This confirms the unanticipated findings that readers interact with the text more effectively during paper-based reading and so are more likely to achieve their academic goals using this medium. However, it is also worth noting that an additional range of e-resources is available to, and used by, readers when reading texts on-screen.

The findings reveal that reading digitally differs from reading printed text. Digital reading engages readers in several processes simultaneously, including searching, watching videos, reading for writing, re-reading, searching again and checking emails. On the other hand, print readers have increased concentration on the reading process, which includes reading, underlining, highlighting, re-reading, and relating ideas.

Moreover, the findings from three sorts of data analysis, reveal the over reliance on the bottom-up process while reading on-screen, which could be related to the language proficiency of the participants. According to Chun and Thompson (2008), readers with lower language proficiency levels employ more bottom-up processes for comprehension than readers with a higher level of language proficiency. However, in the current study, those readers who read the printed text also engaged in reading on-screen. Thus, their over reliance on bottom-up processes while reading on-screen could be due to the lack of familiarity with the on-screen reading processes. This might affect their language level proficiency and temporarily decrease their L2 language knowledge, as they cognitively engage with other processes, such as interacting with the digital functions of the text. In addition, readers might be unaccustomed to engaging deeply and critically with a text on-screen, which results in lower application of the top-down reading processes.

This indicates that readers in the current study successfully engaged with both reading 
formats. According to Alderson et al. (2014), Hersch and Andrews (2012), Kintsch (2005) and Grabe (2008), effective reading consists of and requires the interaction between two reading processes. That is to say, participants comprehended the text better using a top-down approach when reading on paper in order to evaluate, analyze and utilize content. Meanwhile, they comprehended the text via the bottom-up processes, as they aimed to engage more fully with the text. However, during print-based reading, readers are better at achieving more successful outcomes than they are when reading on-screen as they are more engaged with the paper text format than the on-screen one. That is, the top-down and bottom-up approaches were more evenly applied during paper reading than during on-screen reading.

\subsection{Differences and Similarities between Print-based and On-screen Reading}

The following section discusses the differences and similarities between on-screen and print-based reading, attempting to demonstrate the differences and similarities between the reading strategy categories, sub-strategies, processes employed and comprehension outcomes. Interesting differences and similarities were found in the text interaction when using two types of reading formats, print and on-screen. These will be presented in the following sections.

\subsubsection{Differences and Similarities in Reading Processes}

The data showed that readers approached on-screen texts using bottom-up processing and, to a lesser degree, top-down processing. However, during this process, top-down processing was used mainly to evaluate the relevance of the text and its connection to academic purposes. On the other hand, when approaching texts in a printed paper format, readers tended to rely equally on both processes. These findings show that both reading processes are activated during the two reading formats: paper and on-screen. However, the frequency of use of the two reading processes differs. For further clarification, these results are illustrated graphically in

Figure 3, which presents the frequency of the types of reading approaches employed by the postgraduate readers in relation to the two reading formats. 


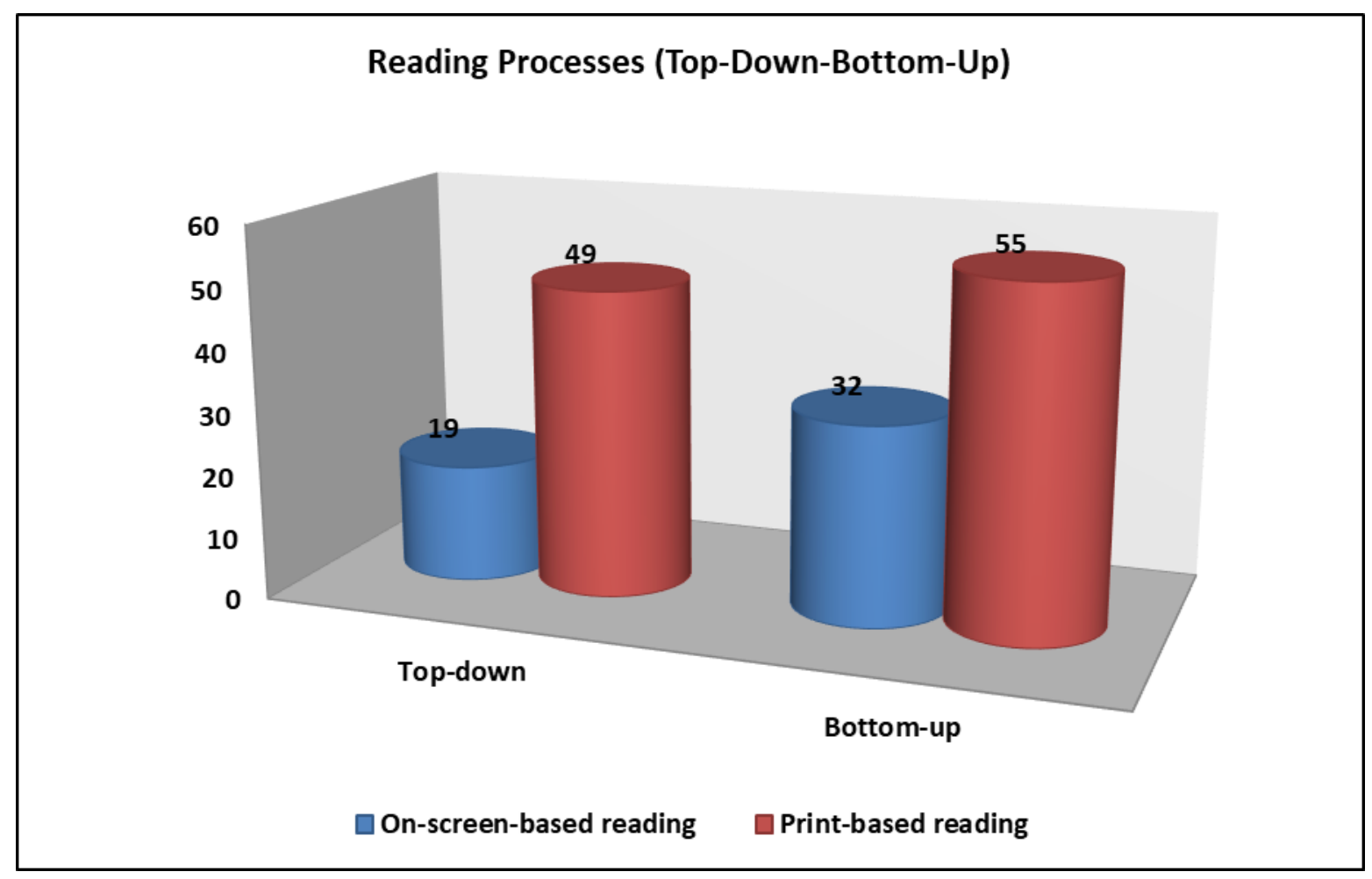

Figure 3. Comparing the employment of the two reading processes (top-down and bottom-up) between the two reading formats (on-screen versus print)

The mean scores of both types of reading processing demonstrate that the readers were relying more on bottom-up (mean $=32$ ) than top-down $($ mean $=19)$ processing while they were reading on-screen texts. On the other hand, during print-based reading, readers employed the two approaches almost equally, (Top-down mean $=49)$ and (Bottom-up mean = $55)$.

\subsubsection{Differences and Similarities in Functional Reading Strategy Categories}

In both reading formats, print and on-screen, readers used a wide repertoire of the same strategies: PROB, SUP, GLOB and CRT. The frequency of use of each of these types of strategy differs in relation to the two formats. A comparison between the frequencies with which various reading strategies were employed during on-screen and on paper reading revealed that all four types of strategy i.e. PROB, SUP, GLOB and CRT were used more frequently when reading on paper than when reading on-screen. It can be seen from

Figure 4 that during on-screen reading, participants employed fewer strategies than when reading on paper. 


\section{Macrothink}

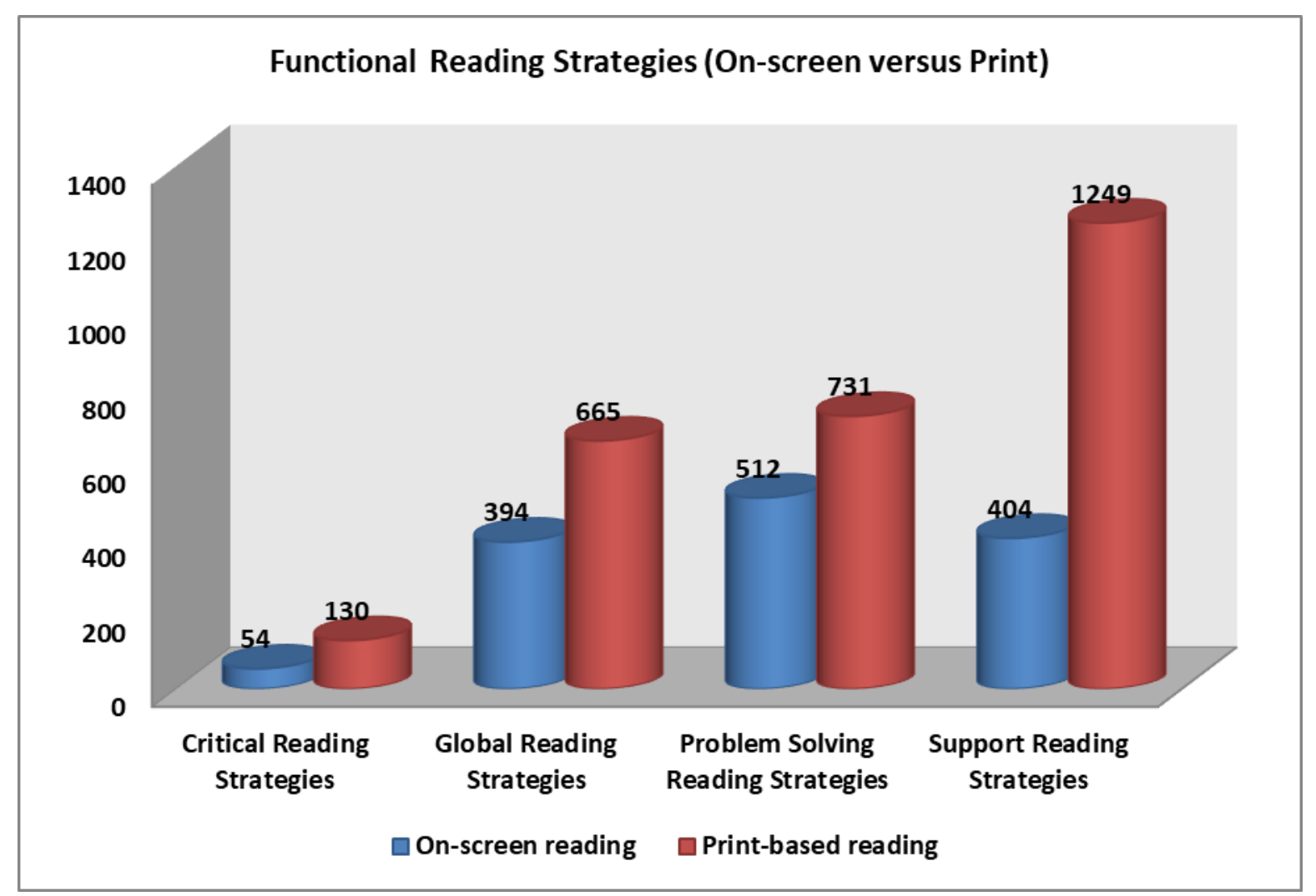

Figure 4. Functional reading strategies - number of instances (on-screen versus print)

Readers employed support reading strategies during their paper reading to a far greater extent (1249) than they employed them during their on-screen reading task (404). Similarly, problem-solving strategies were employed twice as much during the paper reading task (731) as during the on-screen reading task (512). Moreover, readers' use of critical reading strategies when on-screen reading was much less (54) than when they were reading text on paper (130). There was also a slightly higher use of global reading strategies during the paper-reading task (665) than the on-screen reading task (394).

\subsubsection{Differences and Similarities in Sub-strategies}

\section{PROB sub-strategies}

In view of the findings, it is interesting to note that there are differences in the strategies typically employed while reading on-screen and reading printed paper. The analysis of the PROB sub-strategies revealed that readers employed them more frequently during their paper reading task than during their on-screen reading task. These results are illustrated graphically in

Figure 5, which presents the frequency with which PROB sub-strategies were employed in the two formats. 


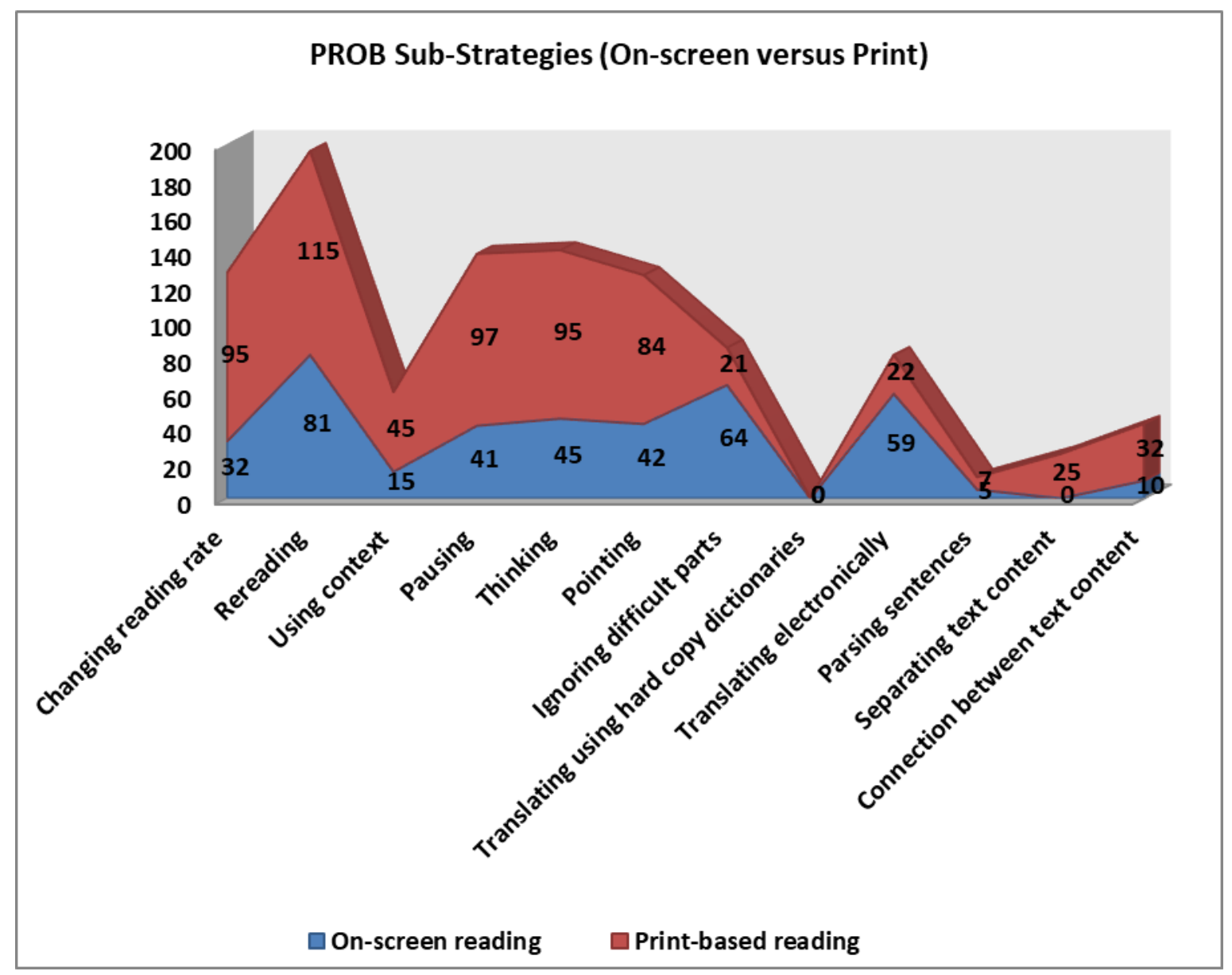

Figure 5. Problem-solving sub-strategies - number of instances (on-screen versus print)

Readers changed their reading speed, used strategies such as re-reading specific sections, pausing and thinking more frequently during print-based reading than on-screen reading. However, they were more likely to ignore difficult sections and look up the translation of words electronically during their on-screen reading than during their print-based reading task. Surprisingly, the readers did not refer to hard copy translations of words when reading in either format.

\section{SUP sub-strategies}

The readers employed SUP sub-strategies more frequently during print-based reading than on-screen reading. For further clarification, these results are illustrated graphically in

Figure 6, which presents the frequency with which various SUP sub-strategies were employed in the two different reading formats. 


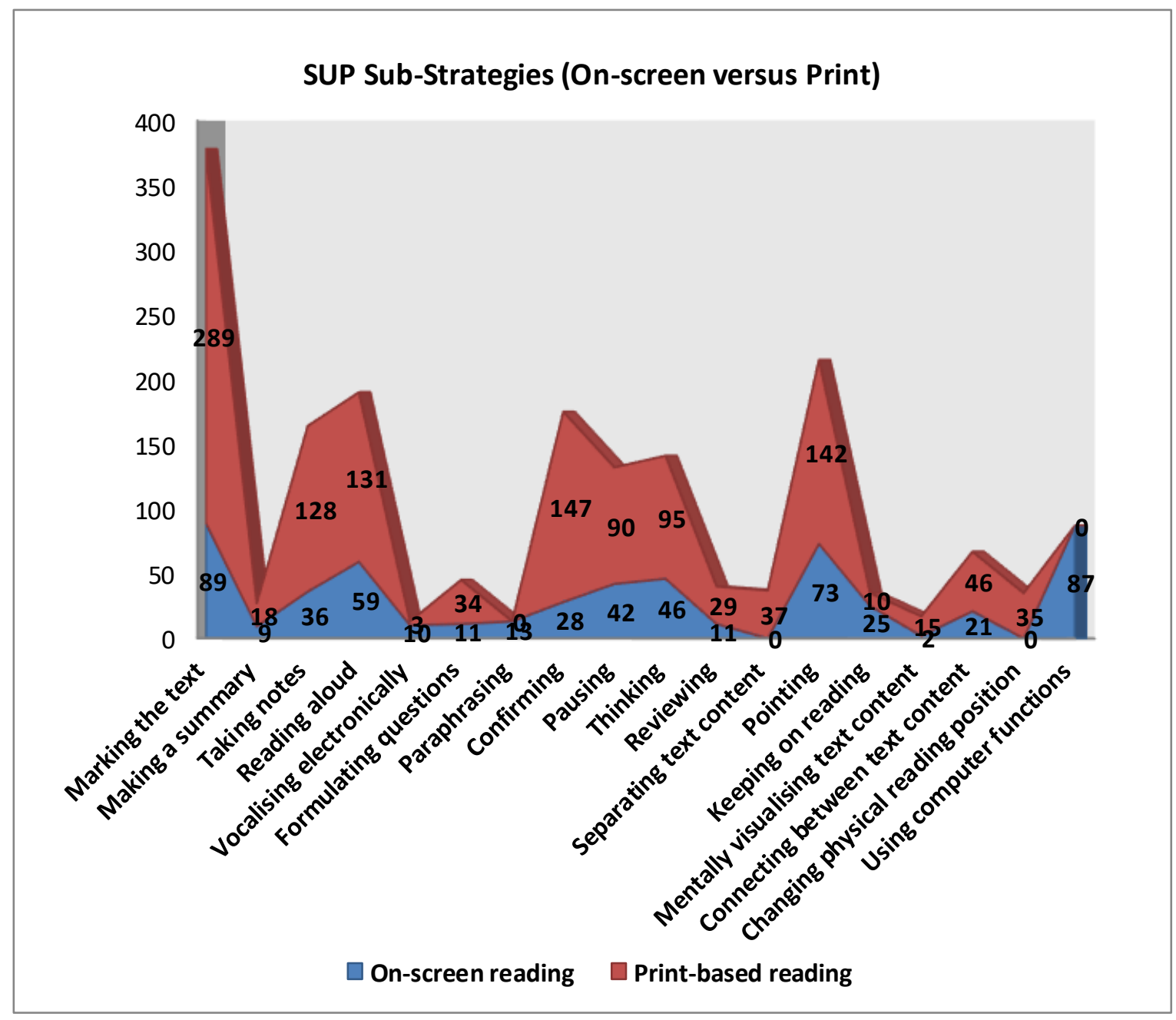

Figure 6. Support sub-strategies - number of instances (on-screen versus print)

Support reading strategies were used less frequently during on-screen reading than during paper reading. Readers marked the text, took notes, pointed, paused, separated sections, reviewed, formulated questions, connected ideas, confirmed and vocalized more frequently during their paper reading task than during their on-screen reading one. On the other hand, readers paraphrased, summarized, ignored difficult parts and vocalized 'electronically' more frequently during their on-screen reading task than during print-based reading. There are a few sub-strategies that were employed in only one of the reading formats, for example, changing reading positions was only applied while reading the paper, whereas digital activities were only applied during on-screen reading. Another sub-strategy that has been employed during print-based reading only is separating sections. The readers sometimes separated sentences or paragraphs in order to support their reading comprehension. However, other readers reported that they separated sentences as they found them too complex to understand. In the latter case therefore, they separated the sentences in order to solve a reading problem. 


\section{GLOB sub-strategies}

A comparison between the applications of the sub-strategies of the GLOB category in the two text formats indicates that some of the GLOB sub-strategies were employed more often during the print-based reading task than the on-screen reading task, while other strategies were more frequently employed during the on-screen reading task than during the print-based reading one. These results are illustrated graphically in

Figure 7, which presents the differences in the frequency with which the GLOB sub-strategies were used in the two reading formats.

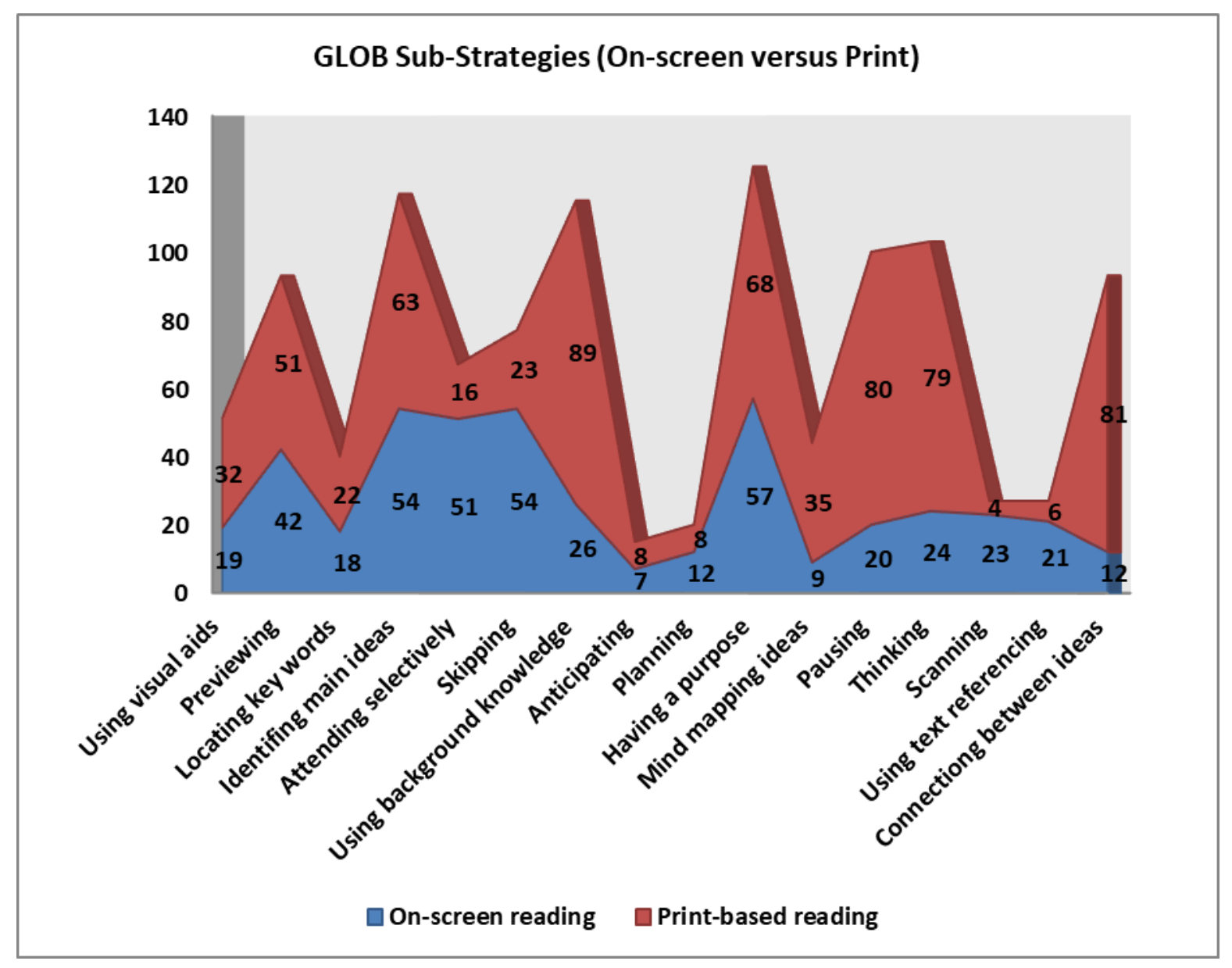

Figure 7. Global sub-strategies - number of instances (on-screen versus print)

Readers employed different strategies such as using references, visual aids, skipping, scanning and ignoring difficult parts, more frequently during their on-screen reading task than during their paper reading task. By contrast, readers employed the background knowledge strategy, pausing, thinking and connecting ideas during the print-based reading task more frequently than the on-screen reading task. This reinforces the conclusion that readers tend to use on-screen reading only as a means of checking information relevant to their academic purposes. Thus, they ignore difficult and detailed passages and do not attempt 
to use strategies to understand them. Readers also use visual aids to help them understand the main ideas of the text, without spending much time reading the detailed information.

\section{CRT sub-strategies}

The analysis of the use of sub-strategies of critical reading clearly revealed that readers applied these sub-strategies more frequently during their paper reading task than during their on-screen reading task. These results are illustrated graphically in

Figure 8, which presents the frequency with which the CRT sub-strategies were applied to the two reading formats.

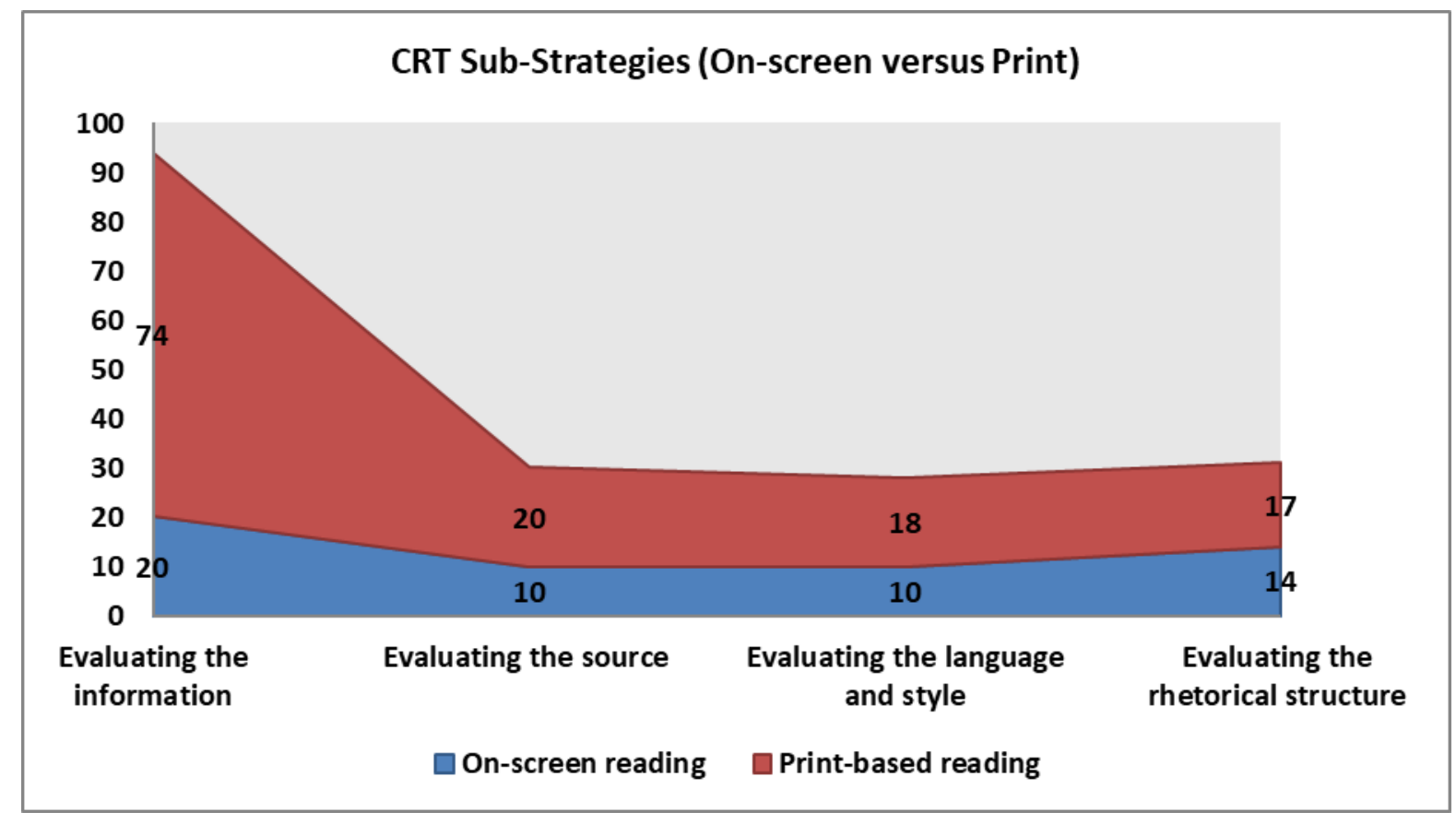

Figure 8. Critical sub-strategies - number of instances (on-screen versus print)

Readers observed the style and the language of the text and evaluated the sources and the information given more frequently during their paper reading task than during their on-screen reading task. This indicates that they read the text presented in hard copy more critically than they read text presented on-screen. Having analyzed and presented on-screen and print-based reading processes, functional strategies, sub-strategies and reading challenges, the next section discusses the comprehension outcomes of the two reading formats: print and on-screen.

\subsection{Comprehension Outcomes}

In the current study the researcher was not aiming to evaluate and compare any product of on-screen and print-based reading. However, when evaluating readers' overall interaction with reading print-based and on-screen texts, and readers' perceptions of on-screen reading, it was apparent that readers are more engaged with print-based texts, employ strategies more frequently and comprehend better when reading these texts. This result could be considered 
to be supported by the results' of earlier studies that specifically compare learning outcomes when reading on-screen and print-based texts. Lam, Lam, Lam and Mcnaught (2009) investigated 12 students' use of academic eBooks and concluded that electronic reading is not useful or practical for academic comprehension and learning. Murat and Ferdi (2014) found that reading on-screen is less efficient than reading from printed paper. Carr (2010) and Liu (2005) demonstrated low comprehension levels for reading on-screen texts compared to reading print-based texts. Solak (2014) found that readers' comprehension text answers based on print-based reading were better by $15 \%$ than readers' comprehension text answers based on screen reading. Kim and Kim (2013), and Mangen et al. (2013) also revealed that students who read texts in print scored significantly better on the reading comprehension test than students who read the texts digitally. Stoop, Kreutzer, and Kircz (2013) found that reading printed text is more effective than reading on-screen text in terms of elaborating and digesting content.

In a similar vein, other researchers have reported that reading comprehension and learning rates are higher when reading traditional text books compared to e-books (Dillion 1992; Mayer et al. 2001). Jeong (2012) examined the effect of reading a traditional book and an e-book on readers' reading comprehension and found that readers had better quiz scores after reading printed books than e-books. In addition, readers' perceptions of on-screen reading in the current study reveals better comprehension and learning outcomes when using printed paper reading texts. In other words, they think that they achieve better outcomes when reading from a printed text. Ji, Michaels and Waterman (2014) reported that the majority of readers said that they usually read more and learn more, when printed reading is supplied. Kang et al. (2009) in a study conducted on junior college students reported a higher level of reading performance when reading hard copies of a book than when reading electronic ones. All these results support the unexpected conclusion of the present study that readers are better engaged with print-based text and consequently achieve better comprehension.

\subsection{Reading Components}

Comparing the multiple components of the two reading formats, print and on-screen, reveals similarities and differences between the two reading formats. It was found that on-screen reading comprehension involves a variety of different elements. In this regard, on-screen reading consists of print-based and on-screen competences and reading capabilities. On the other hand, print based reading involves only print-based competences and reading capabilities. Additionally, on-screen reading comprehension includes digital literacy as an essential element of on-screen reading comprehension.

These results are illustrated graphically in

Figure 9, which presents a proposed model of on-screen reading comprehension components. It consists of two levels, namely on-screen reading comprehension components and print-based reading comprehension components. On-screen reading comprehension components consist of on-screen reading competences, digital literacy, on-screen reading capabilities and print-based reading comprehension components which include content knowledge, print-based reading competences and capabilities: and L2 language proficiency. 


\section{Ml Macrothink}

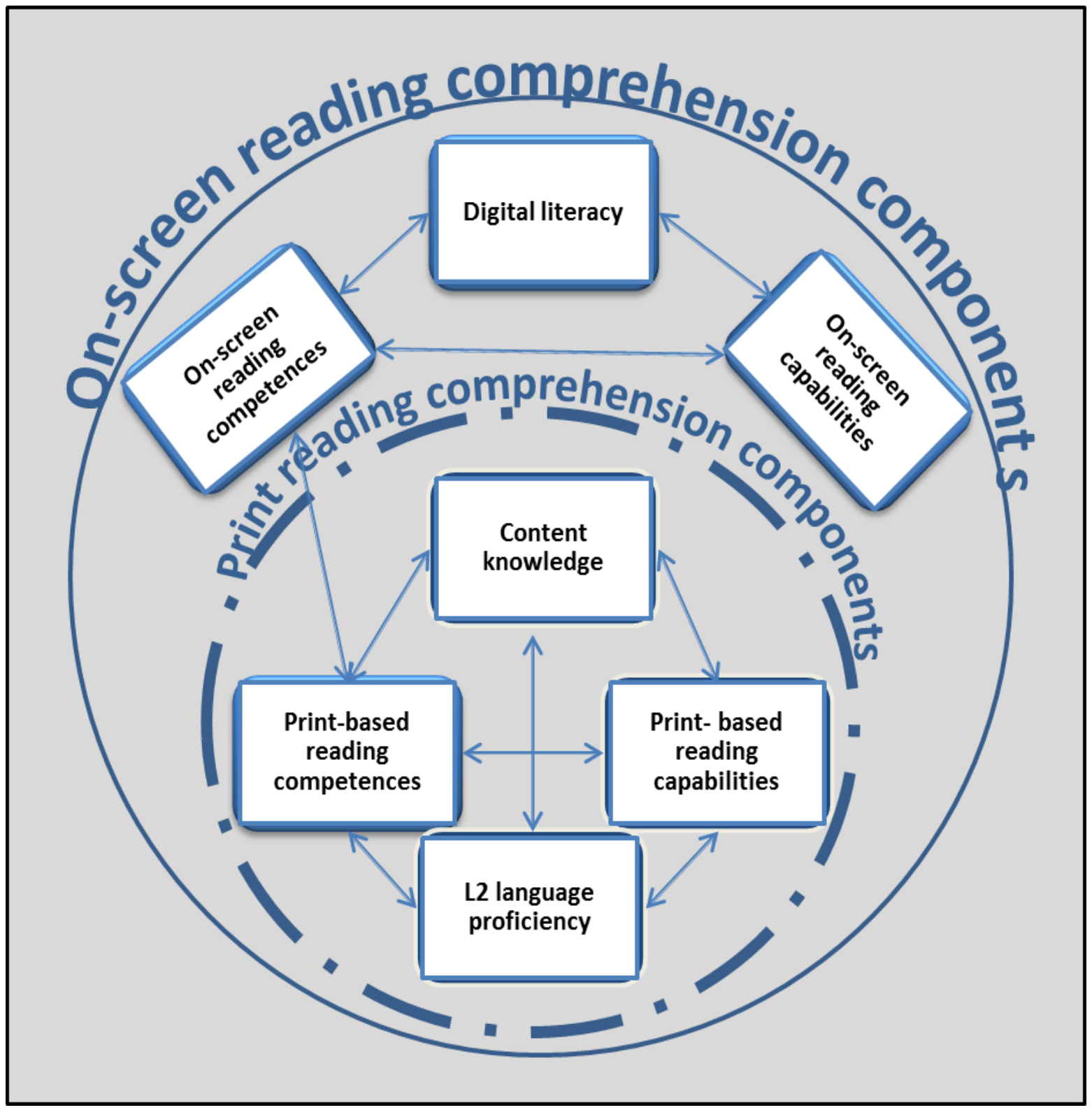

Figure 9. The proposed model of on-screen L2 academic reading comprehension components (based on the research data)

The data revealed that on-screen L2 academic reading comprehension comprises multiple components. Reading comprehension capabilities consist of higher-level reading processes, such as connecting with previous knowledge to comprehend and implementing purposeful reading. In addition, lower-level reading processes can also contribute to reading abilities. For example, strategies such as translating specific words while reading, listening to pronunciation, and reading sentences aloud were regularly employed when reading on-screen. This is consistent with the findings reported by other reading researchers, who found that on-screen reading demands the use of both higher level and lower level reading strategies (Anderson 2003; Chou 2012; Zaki et al. 2009). Both reading formats require readers to employ higher level strategies and lower level strategies to understand the text. Alderson et al. 
(2014) highlighted the essential role of higher level and lower-level reading processes in L2 reading comprehension. Similarly, Grabe and Stoller (2011) stated that lower level reading processes, that include word recognition, syntactic parsing, semantic proposition and formation, are fundamental requirements for reading comprehension. They also highlighted the important role of the higher-level processes, such as background knowledge use and inference during print-based reading to take the basic information out of the text to build comprehension.

With regard to content knowledge, both reading formats appear to include readers' knowledge about the content of a text as one of the main elements that enable and enhance reading comprehension. Alyousef (2006) and Hudson (2007) stressed the important role of readers' background knowledge in L2 reading comprehension. Equally, an important element for comprehending both reading formats is readers' L2 knowledge. Alderson et al. (2014) reported that knowledge of L2 grammar and vocabulary are components of L2 print-based reading proficiency. Alyousef (2006) stated that L2 linguistic knowledge, including vocabulary, structural and formal discourse knowledge, is a component of L2 reading comprehension. Hudson (2007) highlighted the role of breadth and depth of vocabulary knowledge in $\mathrm{L} 2$ reading.

Furthermore, competences (schema) of strategies, L2, content are an essential component of both reading formats. According to Allen and Hancock (2008); Iwai (2011); Maasum and Maarof (2012); Magogwe (2013); Yang (2011); Lian Zhang and Seepho (2013); Zhang and Wu (2009) and Hudson (2007) knowledge about reading strategies has a significant impact on readers' reading comprehension while reading a print-based text. Alyousef (2006) reported that knowledge and skills monitoring are components of L2 reading. Similarly, Mesgar, Bakar and Amir (2012) asserted that awareness of reading strategies is a necessity for on-screen reading. However, on-screen reading requires an additional sort of competence which is not part of the print-based reading, called digital schema. Meanwhile, the differences between the components informing print-based reading comprehension and on-screen reading comprehension are also affected by reading competences and capabilities.

It is important to point out that by identifying and presenting the components of on-screen L2 academic reading, the requirements that enable readers to read and comprehend academic texts on-screen have been clarified. It is suggested that these main components should be treated as a single combined construct with reference to L 2 on-screen academic reading. The researcher in the present study suggests that these findings could be generalizable across L2 readers in different contexts and at different educational levels.

\section{Conclusion}

This study investigated several aspects of readers' print and on-screen reading comprehension. Most importantly, the study was designed to scrutinize readers' digital academic reading comprehension strategies and the processes that they employ to comprehend the on-screen text. The study presented findings regarding which types of reading strategies were most and least-frequently used when students read academic texts on-screen and from printed paper based on the Think-aloud (TA), stimulated recalls (SR), and interviews. The TA and SR 
sessions revealed qualitative explanations of the kind of reading comprehension strategies that readers utilized to support their reading comprehension, solve a problem, evaluate the text, and/or approach the text globally. In this regard, it was found that print-based reading was more effective and led to greater comprehension and learning than on-screen reading. This finding was backed by the readers who employed more strategies and interacted more deeply with printed text than on-screen text. In other words, it can be concluded that readers may not aim to solve their reading comprehension problems as often during on-screen reading as they do during print-based reading. It also seems that they do not aim to obtain a deep understanding of text during on-screen reading but rather to gain a general idea about the text and check its relevance to their academic purposes by translating specific words and skipping sections.

\section{References}

Abraham, L. (2007). Second-language reading comprehension and vocabulary learning with multimedia. Hispania, 90(1), 98-108. Retrieved from http://www.jstor.org/stable/10.2307/20063468

Akyel, A., \& Erçetin, G. (2009). Hypermedia reading strategies employed by advanced learners of English. System, 37(1), 136-152. https://doi.org/10.1016/j.system.2008.05.002

Alderson, J. C., Haapakangas, E.-L., Huhta, A., Nieminen, L., \& Ullakonoja, R. (2014). The Diagnosis of Reading in a Second or Foreign Language. Taylor \& Francis. Retrieved from https://books.google.com/books?id=2VCvBAAAQBAJ\&pgis=1

Allen, K. D., \& Hancock, T. E. (2008). Reading Comprehension Improvement with Individualized Cognitive Profiles and Metacognition. Literacy Research and Instruction, 47(2), 124-139. https://doi.org/10.1080/19388070801938320

Alyousef, H. (2006). Teaching reading comprehension to ESL/EFL learners. Journal of Language and Learning, 5(2), 379-380.

Anderson-Inman. (2009). Supported eText: Literacy scaffolding for students with disabilities. Journal of Special Education Technology, 24(3). Retrieved from http://www.tamcec.org/wp-content/uploads/2009/06/JSETv24n3.pdf\#page=5

Anderson-Inman, L. (2004). Reading on the Web: Making the most of digital text. Wisconsin State Reading Association, 8-14. Retrieved from http://readingcenter.csumb.edu/documents/2007_Handouts/Friday/Anderson_Journal.pdf

Anderson-Inman, L., \& Horney, M. A. (2007). Supported eText: Assistive technology through text transformations. Reading Research Quarterly, 42(1), 153-160. Retrieved from http://onlinelibrary.wiley.com/doi/10.1598/RRQ.42.1.8/abstract

Anderson, N. J. (1999). Exploring Second Language Reading: Issues and Strategies. UK: Heinle \& Heinle Publ Incorporated. Retrieved from http://www.amazon.co.uk/Exploring-Second-Language-Reading-TeacherSource/dp/08384668 50 
Anderson, N. J. (2003). Scrolling, clicking, and reading English: Online reading strategies in a second/foreign language. The Reading Matrix, 3(3), 1-33.

Annand, D. (2008). Learning Efficacy and Cost-effectiveness of Print Versus e-Book Instructional Material in an Introductory Financial Accounting Course David Annand Athabasca University. Journal of Interactive Online Learning, 7(2), 152-164.

Askehave, I., \& Ellerup Nielsen, A. (2005). Digital genres: a challenge to traditional genre theory. Information Technology \& People, 18(2), 120-141. https://doi.org/10.1108/09593840510601504

Basturkmen, H. (2012). A genre-based investigation of discussion sections of research articles in Dentistry and disciplinary variation. Journal of English for Academic Purposes, 11(2), 134-144. https://doi.org/10.1016/j.jeap.2011.10.004

Bhatia, V. K. (2004). Worlds of Written Discourse: A Genre-Based View. London: Continuum. Retrieved from http://books.google.com/books?id=_A8Hf5BHO_QC\&pgis=1

Bolanos, E. (2012). A Comparison of the Reading Strategies Used by Good Readers in Print and Hypertext Environments: Implications and Recommendations for the Improvement. TESOL Journal, 7(2), 2-9. Retrieved from http://www.tesol-journal.com/PDF/V7_A1.pdf

Broek, P. P. den, Lorch, R. F., Linderholm, T., \& Gustafson, M. (2001). The effects of readers' goals on inference generation and memory for texts. Memory \& Cognition, 29(8), 1081-7. Retrieved from http://www.ncbi.nlm.nih.gov/pubmed/11913743

Brown, G. J. (2001). Beyond print: reading digitally. Library Hi Tech, 19(4), 390-399.

Burk, R. (2001). E-book devices and the marketplace: in search of customers. Library Hi Tech, 19(4), 325-331. https://doi.org/10.1108/07378830110411907

Carr, N. (2010). The Shallows: How the internet is changing the way we think, read and remember. Atlantic Books, Limited. Retrieved from http://books.google.com/books?hl=en\&lr=\&id=AsZ1R3196FEC\&pgis=1

Cenoz, J., \& Jessner, U. (2000). English in Europe: The Acquisition of a Third Language. UK and USA: British Library Cataloguing.

Chen, H. (2010). Online reading comprehension strategies among fifth-and sixth-grade general and special education students. Education, Research and Perspectives, 37(2), 79-109.

Retrieved

from http://erpjournal.net/wp-content/uploads/2012/07/ERPV37-2.-Chen-H.-2010.-Online-Readin g-Comprehension-Strategies.pdf

Chen, N.-S., Teng, D. C.-E., \& Lee, C.-H. (2011). Augmenting paper-based reading activity with direct access to digital materials and scaffolded questioning. Computers \& Education, 57(2), 1705-1715. https://doi.org/10.1016/j.compedu.2011.03.013

Chou, I.-C. (2012). Understanding on-screen reading behaviors in academic contexts: a case study of five graduate English-as-a-second-language students. Computer Assisted Language 
Learning, 25(5), 411-433. https://doi.org/10.1080/09588221.2011.597768

Chuene, N. D., Lepota, C. K., \& Hans, R. T. (2014). Using E-Readers in Education Challenges and Opportunities. In 2014 International Conference on Teaching and Learning in Computing and Engineering (pp. 299-305). IEEE Computer Society. https://doi.org/10.1109/LaTiCE.2014.64

Coiro, J., \& Dobler, E. (2007). Reading comprehension on the Internet: Exploring the online comprehension strategies used by sixth-grade skilled readers to search for and locate information. Reading Research Quarterly, 1-91.

Darnton, R. (2009). The Case for Books: Past, Present, and Future. United States of America: PublicAffairs. Retrieved from http://books.google.com/books?id=60eLZTNfi $1 \mathrm{kC} \&$ pgis=1

Day, D., \& Lloyd, M. (2007). Affordances of online technologies: More than the properties of the technology. Australian Educational Computing, 22(2), 17-21. Retrieved from http://eprints.qut.edu.au/17291

Dearden, J. (2014). English as a medium of instruction - a growing global phenomenon. British Council, 1-40.

Demiröz, H. (2010). Reading strategies employed by Esl/Efl students. Cumhuriyet Üniversitesi Sosyal Bilimler Dergisi, 34(2), 81-86. Retrieved from http://193.140.145.170/ojs/index.php/sosyalbilimler/article/view/552

Dillon, A., \& Gushrowski, B. (2000). Genres and the Web: Is the personal home page the first uniquely digital genre? Journal of the American Society for Inforamtion Science, 51(2), 202$205 . \quad$ Retrieved from http://onlinelibrary.wiley.com/doi/10.1002/(SICI)1097-4571(2000)51:2\%3C202::AID-ASI11 \%3E3.0.CO;2-R/full

Dörnyei, Z. (2007). Research Methods in Applied Linguistics: Quantitative, Qualitative, and Mixed Methodologies. China: OUP Oxford. Retrieved from http://books.google.com/books?id=gNh6QgAACAAJ\&pgis=1

Dyson, M., \& Haselgrove, M. (2000). The effects of reading speed and reading patterns on the understanding of text read from screen. Journal of Research in Reading, 23(2), 210-223. Retrieved from http://onlinelibrary.wiley.com/doi/10.1111/1467-9817.00115/abstract

Eshet-alkalai, Y., \& Geri, N. (2009). Congruent versus Incongruent Display: The Effect of Page Layout on Critical Reading in Print and Digital Formats. In Learning in the technological era (pp. 73-80). The Open University of Israel.

Frager, A. M. (1993). Affective Dimensions of Content Area Reading. Journal of Reading, 36(8), 616-622. Retrieved from http://www.jstor.org/discover/10.2307/40033378?uid=47748\&uid=3738032\&uid=2\&uid=3\& uid $=5910784 \&$ uid $=67 \&$ uid $=35022 \&$ uid $=62 \&$ sid $=21102150836083$

Gelderen, van A., Schoonen, R., de Glopper, K., Hulstijn, J., Simis, A., Snellings, P., \& 
Stevenson, M. (2004). Linguistic Knowledge, Processing Speed, and Metacognitive Knowledge in First- and Second-Language Reading Comprehension: A Componential Analysis. Journal of Educational Psychology, 96, 19-30.

Goodfellow, R., \& Lea, M. R. (2013). Introduction: Literacy, the digital, and the university. In R. Goodfellow \& M. R. Lea (Eds.), Literacy in the Digital University: Critical Perspectives on Learning, Scholarship and Technology (1st ed., p. 232). London: Routledge. Retrieved from https://books.google.com/books?id=WVpHAQAAQBAJ\&pgis=1

Grabe, W. (2012). Reading in a Second Language: Moving from Theory to Practice. (C. A. Chapelle \& S. Hunston, Eds.) (4th ed.). United States of America: Cambridge University Press. Retrieved from http://books.google.com/books?id=sWe8xB7xMzcC\&pgis=1

Grabe, W., \& Stoller, F. L. (2011). Teaching and Researching: Reading (Vol. 93). Malaysia, CTP-KHL: British Library Cataloguing. Retrieved from http://books.google.com/books?id=Sv893VPiK24C\&pgis=1

Graesser, A. C. (2012). An Introduction to Strategic Reading Comprehension. In D. McNamara (Ed.), Reading Comprehension Strategies: Theories, Interventions, and Technologies (p. 536). Mahwah, New Jersey: Psychology Press. Retrieved from https://books.google.com/books?id=fMl5AgAAQBAJ\&pgis=1

Gunderson, L. (2008). ESL (ELL) Literacy Instruction: A Guidebook to Theory and Practice (2nd ed., Vol. 1). New York: Routledge.

Hartman, A. (2011). Exploring Adobe Flash CS5. New York: Delmar Cengage Learning. Retrieved from http://books.google.com/books?id=p9SC09-_s8oC\&pgis=1

Hersch, J., \& Andrews, S. (2012). Lexical Quality and Reading Skill: Bottom-Up and Top-Down Contributions to Sentence Processing. Scientific Studies of Reading, 16(3), 240262. https://doi.org/10.1080/10888438.2011.564244

Hewings, M. (2006). Introduction. In M. Hewings (Ed.), Academic Writing in Context: Implications and Applications. United Kingdom: British Library Cataloguing.

Horton, W., Taylor, L., Ignacio, A., \& Hoft, N. L. (1995). The Web Page Design Cookbook: All the Ingredients You Need to Create 5-Star Web Pages (Vol. 1995). United States of America: Katherine Schowalter. Retrieved from http://books.google.com/books?id=g3SFQgAACAAJ\&pgis=1

Hudson, T. (2007). Teaching Second Language Reading: A guide to teaching reading skills for teachers of English as a foreign language. OUP Oxford. Retrieved from http://books.google.com/books?id=kP11RQAACAAJ\&pgis=1

Hyland, K. (2009). Writing in the disciplines: Research evidence for specificity. Taiwan International ESP Journal, 1(1), 5-22. $\quad$ Retrieved from http://www.tespa.org.tw/papers/01/04-Writing in the disciplines-Research evidence for specificity_Ken Hyland.PDF 
Iwai, Y. (2011). The effects of metacognitive reading strategies: pedagogical implications for EFL/ESL teachers. Reading Matrix, 11(2), 150-159. Retrieved from http://readingmatrix.com/articles/april_2011/iwai.pdf

Jafari, S. M., \& Shokrpour, N. (2012). The Reading Strategies Used by Iranian ESP Students to Comprehend Authentic Expository Texts in English. International Journal of Applied Linguistics \& English Literature, 1(4), 102-113. https://doi.org/10.7575/ijalel.v.1n.4p.102

Jeong, H. (2012). A comparison of the influence of electronic books and paper books on reading comprehension, eye fatigue, and perception. The Electronic Library, 30(3), 390-408. https://doi.org/10.1108/02640471211241663

Ji, S. W., Michaels, S., \& Waterman, D. (2014). Print vs. electronic readings in college courses: Cost-efficiency and perceived learning. The Internet and Higher Education, 21, 1724. https://doi.org/10.1016/j.iheduc.2013.10.004

Kang, Y.-Y., Wang, M.-J. J., \& Lin, R. (2009). Usability evaluation of E-books. Displays, 30(2), 49-52. https://doi.org/10.1016/j.displa.2008.12.002

Kendeou, P., Broek, P. van den, White, M. J., \& Lynch, J. (2007). Comprehension in Preschool and Early Elementary Children: Skill Development and Strategy Interventions. In D. S. Mcnamara (Ed.), Reading Comprehension Strategies: Theories, Interventions and Technologies (p. 520). New York, New York, USA: Routledge. Retrieved from http://books.google.com/books?id=cLCqNEGbP6wC\&pgis $=1$

Ketabi, S., Ghavamnia, M., \& Rezazadeh, M. (2012). Hypermedia Reading Strategies Used by Persian Graduate Students in TEFL: A Think-Aloud Study. Reading, 12(1), 39-49. Retrieved from http://www.readingmatrix.com/articles/april_2012/ketabi_ghavamnia_rezazadeh.pdf

Kintsch, W. (2005). An Overview of Top-Down and Bottom-Up Effects in Comprehension : The CI Perspective An Overview of Top-Down and Bottom-Up Effects in Comprehension: The CI Perspective. Discourse Processes, 39(2 \& 3), 37-41.

Koda, K. (2005). Insights Into Second Language Reading: A Cross-Linguistic Approach. United States of America: Cambridge University Press. Retrieved from http://books.google.com/books?hl=en\&lr=\&id=7GMt91Q1BYUC\&pgis=1

Koda, K. (2007). Reading and Language Learning: Crosslinguistic Constraints on Second Language Reading Development. Language Learning, 57(1), 1-44.

Labbo, L. (2006). Literacy pedagogy and computer technologies: Toward solving the puzzle of current and future classroom practices. Australian Journal of Language and Literacy, 29(3), 199-209. Retrieved from http://www.alea.edu.au/documents/item/77

Lam, P., Lam, S. L., Lam, J., \& Mcnaught, C. (2009). Usability and usefulness of eBooks on PPCs: How students ' opinions vary over time The rise of mobile eBooks. Australasian Journal of Educational Technology 2009, 25(1), 30-44. 
Levy, D. (1997). I read the news today, oh boy: reading and attention in digital libraries. In ACM international conference on Digital libraries (pp. 202-211). Philadelphia PA, USA. Retrieved from http://dl.acm.org/citation.cfm?id=263817

Lim, J. M.-H. (2010). Commenting on research results in applied linguistics and education: A comparative genre-based investigation. Journal of English for Academic Purposes, 9(4), 280-294. https://doi.org/10.1016/j.jeap.2010.10.001

Linderholm, T., Cong, X., \& Zhao, Q. (2008). Differences in low and high working-memory capacity readers' cognitive and metacognitive processing patterns as a function of reading for different purposes. Reading Psychology, 29(1), 61-85. Retrieved from http://www.tandfonline.com/doi/abs/10.1080/02702710701568587

Liu, Z. (2005). Reading behavior in the digital environment: Changes in reading behavior over the past ten years. Journal of Documentation, 61(6), 700-712. https://doi.org/10.1108/00220410510632040

Liu, Z. (2008). Paper to digital Document in the Information Age. United States of America: British Library Cataloguing.

Liu, Z., \& Huang, X. (2008). Gender differences in the online reading environment. Journal of Documentation, 64(4), 616-626. https://doi.org/10.1108/00220410810884101

Lomicka, L. L. (1998). "To Gloss or Not to Gloss": An Investigation Of Reading Comprehension Online. Language Learning \& Technology, 1(2), 41-50.

Maasum, T. N. R. T. M., \& Maarof, N. (2012). Empowering ESL Readers with Metacognitive Reading Strategies. Procedia - Social and Behavioral Sciences, 69(Iceepsy), 1250-1258. https://doi.org/10.1016/j.sbspro.2012.12.058

Magogwe, J. M. (2013). Metacognitive awareness of reading strategies of University of Botswana English as Second Language students of different academic reading proficiencies. Reading \& Writing, 4(1), 1-8. https://doi.org/10.4102/rw.v4i1.29

Majid, F. A., Azman, N., \& Jelas, Z. M. (2010). The reading strategies of proficient and less proficient adult readers. Journal of Adult and Continuing Education, 16(1), 21-40. https://doi.org/10.7227/JACE.16.1.4

Mangen, A., Walgermo, B. R., \& Brønnick, K. (2013). Reading linear texts on paper versus computer screen: Effects on reading comprehension. International Journal of Educational Research, 58, 61-68. https://doi.org/10.1016/j.ijer.2012.12.002

Mark, W. (2015). From Computers and the Wed to Mobile Devices and e-Text: The Transition to Digital Reading Continues. In R. J. Spiro, M. DeSchryver, M. S. Hagerman, P. M. Morsink, \& P. Thompson (Eds.), Reading at a Crossroads?: Disjunctures and Continuities in Current Conceptions and Practices (p. 198). Oxon: Routledge.

Marshall, C., \& Brush, A. (2002). From personal to shared annotations. In CHI'02 extended abstracts on Human factors in Computing Systems (pp. 20-25). Minneapolis, MN. Retrieved 
from http://dl.acm.org/citation.cfm?id=506610

Martín, P. (2003). A genre analysis of English and Spanish research paper abstracts in experimental social sciences. English for Specific Purposes, 22, 25-43. Retrieved from http://www.sciencedirect.com/science/article/pii/S0889490601000333

Mesgar, M., Bakar, N., \& Amir, Z. (2012). Online Metacognitive Reading Strategies Used By Postgraduate Esl Readers Of Academic Texts. International Journal of Asian Social Science, 2(10), 1779-1794. Retrieved from http://www.pdoaj.com/pdf-files/ijass pp.1779-1794.pdf

Miller, C., \& Shepherd, D. (2009). Questions for genre theory from the blogosphere. In J. Giltrow \& D. Stein (Eds.), Genres in the Internet: Issues in the Theory of Genre (p. 294). Philadelphia PA, USA: John Benjamins Publishing. Retrieved from https://books.google.com/books?id=Wo3X2Y1nrZUC\&pgis=1

Montelongo, J. a., \& Herter, R. J. (2010). Using Technology to Support Expository Reading and Writing in Science Classes. Science Activities: Classroom Projects and Curriculum Ideas, 47(3), 89-102. https://doi.org/10.1080/00368121003801388

Murat, T., \& Ferdi, B. (2014). Effect of Screen Reading and Reading from Printed out Material on Student Success and Permanency in Introduction to Computer Lesson. TOJET: The Turkish Online Journal of Educational Technology, 13(3), 41.

Nielsen, J. (1990). Hypertext and Hypermedia: United States of America: Library of Congress Cataloging in Publication data.

Olive, T., \& Rouet, J. (2008). Summarizing digital documents: Effects of alternate or simultaneous window display. Applied Cognitive ..., 558, 541-558. https://doi.org/10.1002/acp

Oxford, R., \& Crookall, D. (1989). Research on Language Learning Strategies: Methods, Findings, and Instructional Issues. The Modern Language Journal, 73(4), 404-419.

Ozturk, I. (2007). The textual organisation of research article introductions in applied linguistics: Variability within a single discipline. English for Specific Purposes, 26(1), 25-38. https://doi.org/10.1016/j.esp.2005.12.003

Park, H.-R., \& Kim, D. (2011). Reading-strategy use by English as a second language learners in online reading tasks. Computers \& Education, 57(3), 2156-2166. https://doi.org/10.1016/j.compedu.2011.05.014

Park, Y. (2010). Korean EFL college students' reading strategy use to comprehend authentic expository/technical texts in English. Kansas. Retrieved from http://kuscholarworks.ku.edu/dspace/handle/1808/6639

Park, Y., Zheng, B., Lawrence, J., \& Warschauer, M. (2012). Technology-enhanced reading environments. In M. Thomas, H. Reinders, \& M. Warschauer (Eds.), Contemporary Computer-Assisted Language Learning (Vol. 2012, p. 368). UK and USA: Bloomsbury Publishing Plc. Retrieved from http://books.google.com/books?id=LnsgO8T-dwMC\&pgis=1 
Parodi, G. (2008). Written Genres in University Studies: Evidence from an Academic Corpus of Spanish in Four Disciplines. Perspectives on Writing, 483-501. Retrieved from http://sydneysingles.tomgao.com/genre.pdf\#page $=498$

Piolat, A., Roussey, J.-Y., \& Thunin, O. (1997). Effects of screen presentation on text reading and revising. International Journal of Human-Computer Studies, 47(4), 565-589. https://doi.org/10.1006/ijhc.1997.0145

Plakans, L. (2009). The role of reading strategies in integrated L2 writing tasks. Journal of English for Academic Purposes, 8(4), 252-266. https://doi.org/10.1016/j.jeap.2009.05.001

Primor, L., Pierce, M. E., \& Katzir, T. (2011). Predicting reading comprehension of narrative and expository texts among Hebrew-speaking readers with and without a reading disability. Annals of Dyslexia, 61(2), 242-68. https://doi.org/10.1007/s11881-011-0059-8

Qayyum, M. A. (2008). Capturing the online academic reading process. Information Processing \& Management, 44(2), 581-595. https://doi.org/10.1016/j.ipm.2007.05.005

Qian, D. (2002). Investigating the relationship between vocabulary knowledge and academic reading performance: An assessment perspective. Language Learning, 52(3), 513-536. Retrieved from http://onlinelibrary.wiley.com/doi/10.1111/1467-9922.00193/abstract

Reinking, D. (1994). Electronic literacy. NRRC National Reading Reaserch Center, Perdpective in Reading Research, (4), 1-26.

Reinking, D. (2001). Prevention and Instruction Programs that Promote Literacy Engagement: Multimedia and Engaged Reading in a Digital World. In L. Verhoeven \& C. Snow (Eds.), Literacy and Motivation: Reading Engagement in Individuals and Groups (p. 334). Mahwah, New Jersey: Routledge.

Robson, M. (2013). The English Effect: The impact of English, what it's worth to the UK and why it matters to the world. British Council, 1-24.

Roldán-Riejos, A. M., \& Úbeda-Mansilla, P. (2006). Metaphor use in a specific genre of engineering discourse. European Journal of Engineering Education, 31(5), 531-541. https://doi.org/10.1080/03043790600797145

Ruiying, Y., \& Allison, D. (2004). Research articles in applied linguistics: structures from a functional perspective. English for Specific Purposes, 23(3), 264-279. https://doi.org/10.1016/S0889-4906(03)00005-X

Salmerón, L., Kintsch, W., \& Kintsch, E. (2010). Self-Regulation and Link Selection Strategies in Hypertext. Discourse Processes, 47(3), 175-211. https://doi.org/10.1080/01638530902728280

Samraj, B. (2005). An exploration of a genre set: Research article abstracts and introductions in two disciplines. English for Specific Purposes, 24(2), 141-156. https://doi.org/10.1016/j.esp.2002.10.001

Saricoban, A. (2002). Reading strategies of successful readers through the three phase 
approach. The Reading Matrix, 2(3), 1-16. Retrieved from http://www.readingmatrix.com/articles/saricoban/article.pdf

Shabani, A., Kharaji, M. S., \& Abedi, M. (2012). Reading Behavior of Graduate Students in Digital Environment at University of Isfahan through 2008-2009: A Case Study. International Journal of Information Science and Managment, 10(1), 1-14. Retrieved from http://ijism.ricest.ac.ir/ojs/index.php/ijism/article/view/122

Sharpe, R., Beetham, H., Freitas, S. de, \& Conole, G. (2010). Rethinking Learning for a Digital Age: How Learners are Shaping their Own Experiences. In R. Sharpe, H. Beetham, \& S. de Freitas (Eds.), Rethinking Learning for a Digital Age: How Learners are Shaping their Own Experiences (Vol. 1, p. 256). Oxon: Routledge. Retrieved from https://books.google.com/books?id=WIPFBQAAQBAJ\&pgis=1

Sheorey, R., \& Mokhtari, K. (2001). Differences in the metacognitive awareness of reading strategies among native and non-native readers. System, 29, 431-449. Retrieved from http://www.sciencedirect.com/science/article/pii/S0346251X01000392

Slatin, J. (1994). Reading Hypertext: Order Coherence in a New Medium. In P. Delany \& G. Landow (Eds.), Hypermedia and Literary Studies (Fourth Pri, p. 352). United States of America: MIT Press. from http://books.google.com/books?hl=en\&lr=\&id=RZqfrGVmHiwC\&pgis=1

Snow, C. (2002). Reading for Understanding: Toward an $R \& D$ Program in Reading Comprehension (Google eBook). Rand Corporation. Retrieved from http://books.google.com/books?hl=en\&lr=\&id=R1t9btYnK_EC\&pgis=1

Solak, E. (2014). Computer versus Paper-Based Reading: A Case Study in English Language Teaching Context. Mevlana International Journal of Education, 4(1), 202-211. Retrieved from http://files.eric.ed.gov/fulltext/ED550519.pdf

Soliday, M. (2011). Everyday Genres: Writing Assignments Across the Disciplines. United States of America: Library of Congress Cataloging in Publication data.

Stoop, J., Kreutzer, P., \& G. Kircz, J. (2013). Reading and learning from screens versus print: a study in changing habits. New Library World, 114(9/10), 371-383. https://doi.org/10.1108/NLW-04-2013-0034

Szymanska, A., \& Kaczmarek, A. W. (2011). Reading efficiency in blended learning context. Teaching English with Technology, 11(2), 29-42.

Tereszkiewicz, A. (2010). Genre Analysis of Online Encyclopedias: The Case of Wikipedia (1st ed.). Jagiellonian University Press.

UK, G. (2015). Immigration statistics. Retrieved July 1, 2015, from https://www.gov.uk/government/publications/immigration-statistics-january-to-march-2015/i mmigration-statistics-january-to-march-2015

UKCISA. (2015). UKCISA - International students in UK HE - International student statistics: 
UK higher education. Retrieved July 1, 2015, from http://www.ukcisa.org.uk/Info-for-universities-colleges--schools/Policy-research--statistics/R esearch--statistics/International-students-in-UK-HE/\#

Varaprasad, C. (1996). Some Classroom Strategies: Developing Critical Literacy Awareness. Forum, 35(3), $1997 . \quad$ Retrieved from http://www.eric.ed.gov/ERICWebPortal/search/detailmini.jsp?_nfpb=true\&_\&ERICExtSearc h_SearchValue_0=EJ593323\&ERICExtSearch_SearchType_0=no\&accno=EJ593323

Wallace, C. (2001). Reading. In R. Carter \& D. Nunan (Eds.), The Cambridge Guide to Teaching English to Speakers of Other Languages (p. 274). United Kingdom: Cambridge University Press.

Wingate, U. (2015). Academic Literacy and Student Diversity: The Case for Inclusive Practice. Bristol: Library of Congress Cataloging in Publication data.

Wood, A. (2001). International scientific English: The language of research scientists around the world. In J. Flowerdew \& M. Peacock (Eds.), Research Perspectives on English for Academic Purposes (pp. 71-83). United Kingdom: Cambridge University Press.

Wright, M., \& Brown, P. (2006). Reading in a modern foreign language: exploring the potential benefits of reading strategy instruction. Language Learning Journal, 33(1), 22-33. Retrieved from http://www.tandfonline.com/doi/abs/10.1080/09571730685200071

Yang, K.-L. (2011). Structures of cognitive and metacognitive reading strategy use for reading comprehension of geometry proof. Educational Studies in Mathematics, 80(3), 307326. https://doi.org/10.1007/s10649-011-9350-1

Yoshida, M. (2012). The interplay of processing task, text type, and proficiency in L2 reading. Reading in a Foreign Language, 24(1), 1-29.

Yutdhana, S. (2007). Online Reading Strategies Used by Graduate Students. Retrieved on September, (2550), 109-123.

Zaki, I., Hassan, F., \& Razali, A. B. (2009). ESL Students' Online and Offline Reading Strategies: Scrolling, Clicking, Flipping and Reading. Asian Journal of University Education, $4(2), 61-78$.

Zhang, L., \& Seepho, S. (2013). Metacognitive strategy use and academic reading achievement: Insights from a Chinese context. Electronic Journal of Foreign Language Teaching, 10(1), 54-69. Retrieved from http://e-flt.nus.edu.sg/v10n12013/zhang.pdf

Zhang, L., \& Wu, A. (2009). Chinese senior high school EFL students' metacognitive awareness and reading-strategy use. Reading in a Foreign Language, 21(1), 37-59. Retrieved from http://nflrc.hawaii.edu/RFL/April2009/articles/zhang.pdf

Zhang, S., \& Duke, N. (2008). Strategies for Internet Reading with Different Reading Purposes: A Descriptive Study of Twelve Good Internet Readers. Journal of Literacy Research, 40(1), 128-162. https://doi.org/10.1080/10862960802070491 


\section{Copyright Disclaimer}

Copyright for this article is retained by the author(s), with first publication rights granted to the journal.

This is an open-access article distributed under the terms and conditions of the Creative Commons Attribution license (http://creativecommons.org/licenses/by/3.0/). 